\title{
Toxicity responses of $\mathrm{Cu}$ and $\mathrm{Cd}$ : the involvement of miRNAs and the transcription factor SPL7
}

\author{
Heidi Gielen, Tony Remans, Jaco Vangronsveld and Ann Cuypers * (D)
}

\begin{abstract}
Background: MicroRNAs are important posttranscriptional regulators of gene expression playing a role in developmental processes as well as in stress responses, including metal stress responses. Despite the identification of several metal-responsive miRNAs, the regulation and the role of these miRNAs and their targets remain to be explored. In this study, miRNAs involved in the response to $\mathrm{Cd}$ and $\mathrm{Cu}$ excess in Arabidopsis thaliana are identified. In addition, the involvement of the transcription factor SPL7, namely the key regulator of Cu homeostasis, in these metal stress responses is demonstrated by the use of an spl7 knockout mutant. Furthermore, more insight is given in the $\mathrm{Cd}$-induced $\mathrm{Cu}$ deficiency response through determining the effects of adding supplemental $\mathrm{Cu}$ to Cd-exposed plants.

Results: Thirteen miRNAs were identified in response to $\mathrm{Cu}$ and $\mathrm{Cd}$ excess in $\mathrm{A}$. thaliana. Several of these miRNAs (miR397a, miR398b/c and miR857) were oppositely affected under Cu and Cd exposure. The induced expression of these miRNAs after $\mathrm{Cd}$ exposure was totally abolished in the spl7 mutant (SQUAMOSA promoter binding protein like7), indicating a major role for SPL7 in the Cd response. Plants exposed to Cd showed a higher Cu content in the roots, whereas the Cu content in the leaves of the spl7 mutant was reduced. Furthermore, the $\mathrm{Cd}$-induced $\mathrm{Cu}$ deficiency response disappeared when supplemental Cu was added.

Conclusions: Copper- and Cd-responsive miRNAs were identified and several of them are SPL7-dependently regulated. SPL7 seems to be a shared component between both the Cu toxicity and the Cd toxicity response, yet oppositely regulated, that is inactivated after Cu exposure and activated after Cd exposure. Since SPL7 is the key regulator of $\mathrm{Cu}$ homeostasis, and $\mathrm{Cd}$ affects the $\mathrm{Cu}$ homeostasis, we hypothesize that SPL7 is activated in response to $\mathrm{Cd}$ possibly due to a $\mathrm{Cd}$-induced $\mathrm{Cu}$ deficiency. Since adding additional $\mathrm{Cu}$ to $\mathrm{Cd}$-exposed plants resulted in the disappearance of the Cu deficiency response, Cd possibly provokes Cu deficiency, thereby activating SPL7 and inducing subsequently the Cu deficiency response.
\end{abstract}

Keywords: Copper (Cu), Cadmium (Cd), miRNA, SPL7, Arabidopsis, Metal stress, Cu deficiency, Cu homeostasis

\section{Background}

Plants require mechanisms to control growth, development and stress responses and therefore an accurate regulation of gene expression is essential. In recent years, the recognition of microRNAs (miRNAs) as important posttranscriptional regulators of gene expression has emerged. MiRNAs are non-protein coding small endogenous RNAs of approximately 21 nucleotides that

\footnotetext{
* Correspondence: ann.cuypers@uhasselt.be

Environmental Biology, Centre for Environmental Sciences, Hasselt University, Agoralaan Building D, Diepenbeek B-3590, Belgium
}

are complementary with target mRNA thereby causing its translational repression or cleavage [1].

Over the last decade, cloning and sequencing of small RNAs and computational analysis have revealed many miRNAs. Most of these annotated miRNAs have a role in the regulation of developmental processes, like organ morphogenesis and polarity, meristem boundary, floral patterning, vascular development, lateral root development and stomatal development [2-6]. However, different functional studies also showed the participation of miRNAs in stress responses. Liu et al [7] identified 14 miRNAs induced by high-salinity, drought and low 
temperature in Arabidopsis thaliana on a microarraybased analysis, among which miR168, miR171 and miR396 responded to all three stresses. MiR395, negatively regulating ATP sulfurylases and a sulphate transporter, was strongly induced upon sulphate starvation [8-10]. In addition, phosphate starvation induced the expression of miR399, which targets an E2 conjugase PHOSPHATE2, that functions upstream of a subset of phosphate starvation-induced genes [11-13]. Additionally, Pant et al. [14] identified also other $\mathrm{P}$ - and $\mathrm{N}$-starvation responsive miRNAs in $A$. thaliana. These results demonstrate that miRNAs are affected by a fluctuating nutrient availability and are essential in regulating nutrient homeostasis.

Besides this, miRNAs are also involved in responses to metal stress in diverse plant species [15]. Zhou et al. [16] identified six miRNAs responsive to $\mathrm{Cd}$, mercury $(\mathrm{Hg})$ and aluminium (Al) in Medicago truncatula. Recent studies also reported altered expression of some miRNAs in Brassica napus $[17,18]$ and in rice $[19,20]$ after $\mathrm{Cd}$ exposure. It should be noted however that different metals can have different responses upon miRNA expression. On the one hand, the expression of miR398 is downregulated by copper $(\mathrm{Cu})$ and iron $(\mathrm{Fe})$, causing increased copper/zinc superoxide dismutase (CSD) expression [21,22]. On the other hand, excess cadmium (Cd) induces miR398 and this response is also seen under low $\mathrm{Cu}$ availability $[22,23]$. The induction of the miR398 expression under $\mathrm{Cu}$ deprivation is regulated by the active transcription factor SQUAMOSA promoter binding protein-like7 (SPL7) assumed to be a central regulator in $\mathrm{Cu}$ homeostasis [24].

Despite these examples, information about other miRNAs involved in the response to $\mathrm{Cd}$ and $\mathrm{Cu}$ excess in $A$. thaliana is still rather scarce. In this study, we used an RT-qPCR based pri-miRNA platform [14] to identify $\mathrm{Cd}$ - and $\mathrm{Cu}$-responsive (pri-)miRNAs. The expression of their target genes was measured to unravel the role of these miRNAs in the $\mathrm{Cd}$ and $\mathrm{Cu}$ stress response. In addition, the involvement of the transcription factor SPL7 in these metal stress responses was demonstrated by the use of an $s p l 7$ knockout mutant and more insight was gained in the $\mathrm{Cd}$-induced $\mathrm{Cu}$ deficiency response through determining the impact of adding supplemental $\mathrm{Cu}$ to $\mathrm{Cd}$-exposed plants.

\section{Results \\ Plant fresh weight is reduced after exposure to $\mathrm{Cu}$ and Cd}

Root and leaf fresh weight (FW) of wildtype (WT) plants were determined in control conditions and after exposure to $0.5 \mu \mathrm{M} \mathrm{Cu}$ and $5 \mu \mathrm{M} \mathrm{Cd}$ for $0,2,24$ and $72 \mathrm{~h}$ (Fig. 1). The FW of the roots and leaves increased over time in all conditions. However, after $72 \mathrm{~h}$ exposure to $\mathrm{Cd}$ and $\mathrm{Cu}$ root FW was significantly lower compared to controls, while leaf FW was not.

\section{Exposure to excess $\mathrm{Cu}$ and $\mathrm{Cd}$ induces lipid peroxidation}

Since excess metals are considered to affect plasma membranes as a primary target, lipid peroxidation in the roots and leaves of $\mathrm{Cu}$ - and $\mathrm{Cd}$-exposed plants was determined (Fig. 2). In the roots, a significant increase in lipid peroxidation was found in $\mathrm{Cu}$-exposed plants already after $2 \mathrm{~h}$ of exposure, while in the Cd-exposed roots, there was only a significant increase in lipid peroxidation from $24 \mathrm{~h}$ onwards. Lipid peroxidation was significantly higher in $0.5 \mu \mathrm{M} \mathrm{Cu}$-exposed roots than in the roots after $5 \mu \mathrm{M} \mathrm{Cd}$ exposure, but for both metals the increase in lipid peroxidation did not increase further over time. No changes in lipid peroxidation were detected in the leaves after $0.5 \mu \mathrm{M} \mathrm{Cu}$ and $5 \mu \mathrm{M} \mathrm{Cd}$ exposure.

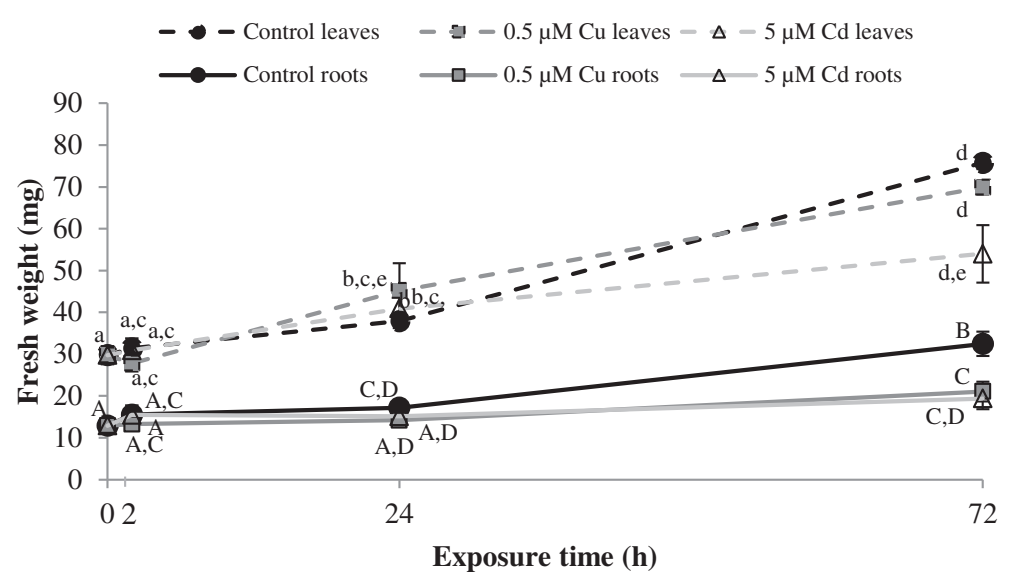

Fig. 1 Fresh weight in roots and leaves of $A$. thaliana plants. Nineteen-days-old plants were exposed for 2,24 or $72 \mathrm{~h}$ to $5 \mu \mathrm{M} C \mathrm{CSO} \mathrm{A}_{4}, 0.5 \mu \mathrm{M}$ $\mathrm{CuSO}_{4}$ or grown under control conditions. Data are mean \pm S.E. of 8 biological replicates. Significant differences $(P<0.05)$ after non-parametrical ANOVA test (Kruskal-Wallis) and correction with pairwise Wilcoxon rank sum test are indicated with different capital (roots) or small (leaves) letters 


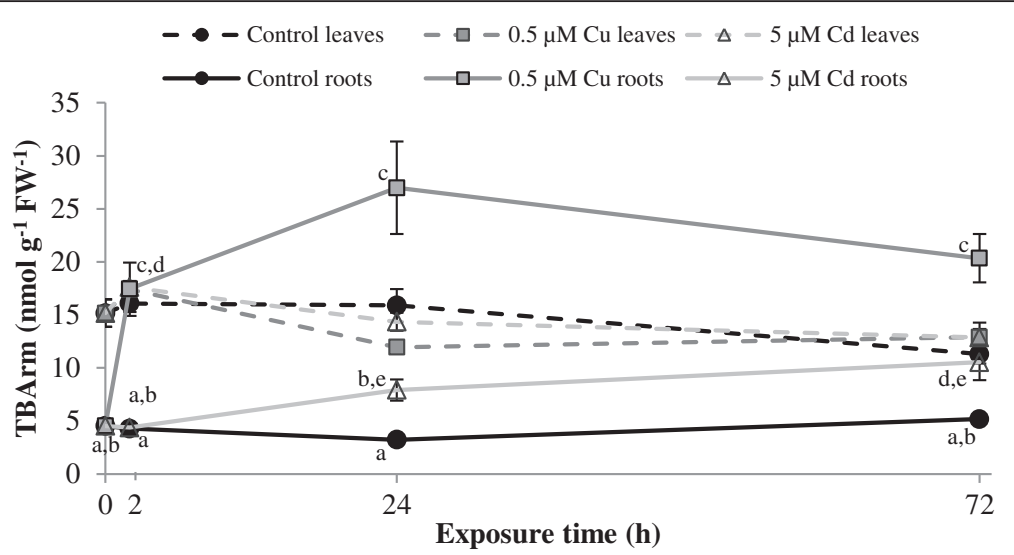

Fig. 2 Lipid peroxidation in roots and leaves of A. thaliana plants. Nineteen-days-old plants were exposed for 2, 24 or $72 \mathrm{~h}$ to $5 \mu \mathrm{M} C \mathrm{CSO}{ }_{4}$, $0.5 \mathrm{MM} \mathrm{CuSO}_{4}$ or grown under control conditions. Data are mean \pm S.E. of at least 3 biological replicates. Significant differences $(P<0.05)$ after two-way ANOVA test and Tukey correction are indicated with different small letters (roots)

\section{Several miRNAs are $\mathrm{Cd}$ and/or Cu responsive}

To determine the involvement of miRNAs in $\mathrm{Cd}$ and $\mathrm{Cu}$ stress responses in $A$. thaliana, we screened the primiRNA expression levels of 180 miRNAs (Additional file 1: Table S1) using an RT-qPCR platform [14]. Based on a threshold (at least 2.5 fold change in normalized expression), thirteen $\mathrm{Cd}$ and/or $\mathrm{Cu}$ responsive pri-miRNAs were identified in roots and leaves. In the roots, six primiRNAs were differentially expressed after $0.5 \mu \mathrm{M} \mathrm{Cu}$ exposure and eleven after exposure to $5 \mu \mathrm{M} \mathrm{Cd}$ (Table 1).

Table 1 Gene expression levels of pri-miRNAs in roots and leaves of A. thaliana plants. Nineteen-days-old plants were exposed for 2, 24 or $72 \mathrm{~h}$ to $0.5 \mathrm{MM} \mathrm{CuSO}_{4}, 5 \mu \mathrm{M} \mathrm{CdSO}_{4}$ or grown under control conditions. Only the pri-miRNAs with an expression level that is 2.5 times up (green) or down (red) regulated are shown. Transcript levels were calculated relative to the non-exposed plants at each time point. Data are mean \pm S.E. of 3 biological replicates. (ND, not detected after 40 cycli)

\begin{tabular}{|c|c|c|c|c|c|c|c|}
\hline & & \multicolumn{3}{|c|}{$0.5 \mu \mathrm{M} \mathrm{Cu}$} & \multicolumn{3}{|c|}{$5 \mu \mathrm{M} \mathrm{Cd}$} \\
\hline & & $2 \mathrm{~h}$ & $24 \mathrm{~h}$ & $72 \mathrm{~h}$ & $2 \mathrm{~h}$ & $24 \mathrm{~h}$ & $72 \mathrm{~h}$ \\
\hline \multirow{13}{*}{$\begin{array}{l}\mathbf{L} \\
\mathbf{E} \\
\mathbf{A} \\
\mathbf{V} \\
\mathbf{E} \\
\mathbf{S}\end{array}$} & pri-miR157a & $2.46 \pm 0.36$ & $1.17 \pm 0.16$ & $1.69 \pm 0.10$ & $1.71 \pm 0.41$ & $0.45 \pm 0.07$ & $1.25 \pm 0.14$ \\
\hline & pri-miR163 & $1.14 \pm 0.09$ & $0.87 \pm 0.12$ & $1.89 \pm 0.44$ & $1.09 \pm 0.07$ & $1.67 \pm 0.47$ & $2.23 \pm 0.20$ \\
\hline & pri-miR167e & ND & ND & ND & ND & $2.42 \pm 0.65$ & $3.49 \pm 0.59$ \\
\hline & pri-miR169c & $1.18 \pm 0.07$ & $1.16 \pm 0.37$ & $0.44 \pm 0.07$ & $1.35 \pm 0.20$ & $1.11 \pm 0.23$ & $0.56 \pm 0.18$ \\
\hline & pri-miR395b & $1.55 \pm 0.42$ & $0.45 \pm 0.04$ & $0.55 \pm 0.21$ & $1.12 \pm 0.25$ & $1.29 \pm 0.29$ & $8.01 \pm 4.70$ \\
\hline & pri-miR395c & $2.85 \pm 0.69$ & $0.86 \pm 0.38$ & $0.99 \pm 0.33$ & $1.58 \pm 0.21$ & $4.29 \pm 0.60$ & $3.40 \pm 1.93$ \\
\hline & pri-miR397a & $0.82 \pm 0.40$ & $1.32 \pm 0.36$ & $0.75 \pm 0.37$ & $0.95 \pm 0.30$ & $2.71 \pm 0.77$ & $5.22 \pm 0.13$ \\
\hline & pri-miR398a & $13.93 \pm 6.54$ & $4.95 \pm 1.79$ & $0.85 \pm 0.20$ & $11.30 \pm 6.10$ & $175.57 \pm 24.02$ & $43.71 \pm 8.61$ \\
\hline & pri-miR398b & $1.38 \pm 0.08$ & $0.19 \pm 0.02$ & $0.08 \pm 0.02$ & $1.86 \pm 0.31$ & $2.54 \pm 1.01$ & $4.56 \pm 0.52$ \\
\hline & pri-miR398c & $1.52 \pm 0.03$ & $0.17 \pm 0.03$ & $0.09 \pm 0.02$ & $2.28 \pm 0.50$ & $2.74 \pm 1.22$ & $6.32 \pm 0.42$ \\
\hline & pri-miR826 & $1.22 \pm 0.09$ & $0.69 \pm 0.04$ & $1.08 \pm 0.04$ & $0.67 \pm 0.04$ & $0.02 \pm 0.01$ & $0.12 \pm 0.01$ \\
\hline & pri-miR847 & $1.82 \pm 0.45$ & $3.01 \pm 1.52$ & $2.90 \pm 0.51$ & $1.83 \pm 0.15$ & $16.33 \pm 3.11$ & $1.15 \pm 0.30$ \\
\hline & pri-miR857 & ND & ND & ND & ND & $78.34 \pm 24.31$ & $18.16 \pm 3.38$ \\
\hline \multirow{13}{*}{$\begin{array}{l}\mathbf{R} \\
\mathbf{O} \\
\mathbf{O} \\
\mathbf{T} \\
\mathbf{S}\end{array}$} & pri-miR157a & ND & ND & ND & ND & $16.17 \pm 3.41$ & $29.13 \pm 14.88$ \\
\hline & pri-miR163 & $0.70 \pm 0.11$ & $0.48 \pm 0.09$ & $0.57 \pm 0.12$ & $1.05 \pm 0.08$ & $0.21 \pm 0.03$ & $0.22 \pm 0.03$ \\
\hline & pri-miR167c & $0.63 \pm 0.04$ & $1.01 \pm 0.10$ & $0.76 \pm 0.06$ & $1.73 \pm 0.20$ & $1.78 \pm 0.61$ & $1.85 \pm 0.25$ \\
\hline & pri-miR169c & $0.42 \pm 0.19$ & $0.18 \pm 0.15$ & $0.28 \pm 0.07$ & $1.24 \pm 0.66$ & $0.30 \pm 0.10$ & $0.25 \pm 0.03$ \\
\hline & pri-miR395b & $1.30 \pm 0.42$ & $0.29 \pm 0.09$ & $0.77 \pm 0.30$ & $2.23 \pm 0.44$ & $0.68 \pm 0.01$ & $1.72 \pm 1.10$ \\
\hline & pri-miR395c & $2.81 \pm 0.51$ & $0.32 \pm 0.06$ & $0.51 \pm 0.08$ & $2.74 \pm 0.46$ & $1.49 \pm 0.16$ & $1.70 \pm 0.40$ \\
\hline & pri-miR397a & ND & ND & ND & ND & $236.34 \pm 24.34$ & $58.95 \pm 13.76$ \\
\hline & pri-miR398a & $233.80 \pm 7.95$ & $15.70 \pm 6.79$ & $0.41 \pm 0.31$ & $448.79 \pm 92.28$ & $18.37 \pm 0.80$ & $2.14 \pm 0.47$ \\
\hline & pri-miR398b & $0.79 \pm 0.17$ & $0.60 \pm 0.10$ & $0.78 \pm 0.04$ & $1.24 \pm 0.12$ & $2.48 \pm 0.13$ & $4.53 \pm 0.44$ \\
\hline & pri-miR398c & $0.85 \pm 0.19$ & $0.45 \pm 0.05$ & $0.75 \pm 0.02$ & $1.34 \pm 0.10$ & $2.98 \pm 0.25$ & $3.82 \pm 1.08$ \\
\hline & pri-miR826 & $0.34 \pm 0.04$ & $0.58 \pm 0.10$ & $0.55 \pm 0.08$ & $0.18 \pm 0.02$ & $0.04 \pm 0.02$ & $0.09 \pm 0.01$ \\
\hline & pri-miR847 & $0.57 \pm 0.11$ & $11.47 \pm 0.78$ & $2.43 \pm 0.76$ & $0.51 \pm 0.16$ & $11.92 \pm 2.18$ & $5.57 \pm 0.27$ \\
\hline & pri-miR857 & ND & ND & ND & $\mathrm{ND}$ & $481.05 \pm 141.74$ & $1650.32 \pm 658.55$ \\
\hline
\end{tabular}


In the leaves, five pri-miRNAs exhibited a different expression after exposure to $0.5 \mu \mathrm{M} \mathrm{Cu}$ and ten primiRNAs after $5 \mu \mathrm{M}$ Cd exposure (Table 1).

Metal exposure changed the expression of miRNAs already after short exposure time. Three miRNAs had an altered expression at the earliest time-point of $2 \mathrm{~h}$ : in roots and leaves an upregulation of pri-miR395c after $\mathrm{Cu}$ exposure and of pri-miR398a after $\mathrm{Cd}$ and $\mathrm{Cu}$ exposure was observed, while a downregulation of pri-miR826 in $\mathrm{Cu}-$ and $\mathrm{Cd}$-exposed roots was noticed. However, most of the responsive pri-miRNAs were induced or repressed after $24 \mathrm{~h}$ and $72 \mathrm{~h}$ of exposure (Table 1). A time-dependent strengthening of the effect only seems to be the case for the induction of pri-miR857 expression in the roots of $5 \mu \mathrm{M}$ Cd-exposed plants on one hand and for the reduction of pri-miR398b and primiR398c expression in the leaves after $0.5 \mu \mathrm{M} \mathrm{Cu}$ exposure on the other hand (Table 1). The induced expression of pri-miR398a in the $\mathrm{Cd}$ - and $\mathrm{Cu}$-exposed roots and in the $\mathrm{Cu}$-exposed leaves diminished over time and even disappeared after $72 \mathrm{~h}$ (Table 1).

Some pri-miRNAs showed an opposite expression pattern after exposure to $\mathrm{Cu}$ or $\mathrm{Cd}$. The expressions in the leaves of pri-miR398b and c were repressed after $24 \mathrm{~h}$ and
$72 \mathrm{~h}$ of $\mathrm{Cu}$ exposure and induced after $24 \mathrm{~h}$ and $72 \mathrm{~h}$ of $\mathrm{Cd}$ exposure (Table 1). Moreover, several pri-miRNAs seemed to be $\mathrm{Cd}$-specific in this experimental design, by which is meant that these pri-miRNAs (in roots: primiR157a, pri-miR397a and pri-miR857; in leaves: primiR167c and pri-miR857) were only expressed after exposure to $\mathrm{Cd}$ and not (or very lowly) expressed in control conditions as well as after $\mathrm{Cu}$ exposure (Table 1).

\section{Target gene expression levels of $\mathrm{Cd}$ - and Cu-responsive miRNAs}

Since miRNAs negatively regulate their target mRNA, identification of these targets provides knowledge about the pathways where these miRNAs are involved in. To determine if the $\mathrm{Cd}$ - and/or $\mathrm{Cu}$-induced differences in pri-miRNA expressions were translated into altered target expression levels under these conditions, a gene expression analysis of several of these targets (validated by $[9,23,25])$ was performed after $24 \mathrm{~h}$ and $72 \mathrm{~h}$ exposure to $0.5 \mu \mathrm{M} \mathrm{Cu}$ or $5 \mu \mathrm{M} \mathrm{Cd}$ (Table 2). There were almost no alterations in target gene expressions in plants exposed to $0.5 \mu \mathrm{M} \mathrm{Cu}$. Only in the leaves after $72 \mathrm{~h}$ of $\mathrm{Cu}$ exposure, the slightly reduced expression of pri-miR395b (Table 1) was translated into a significant upregulation

Table 2 Gene expression levels of pri-miRNA targets in roots and leaves of A. thaliana plants. Nineteen-days-old plants were exposed for 24 or $72 \mathrm{~h}$ to $0.5 \mu \mathrm{M} \mathrm{CuSO}_{4}, 5 \mu \mathrm{M} \mathrm{CdSO}_{4}$ or grown under control conditions. Transcript levels were calculated relative to the non-exposed plants at each time point. Data are mean \pm S.E. of 3 biological replicates. Significant differences $(P<0.05)$ relative to the non-exposed plants at each time point after one-way ANOVA test and Tukey correction are indicated in color (upregulation, green; downregulation, red)

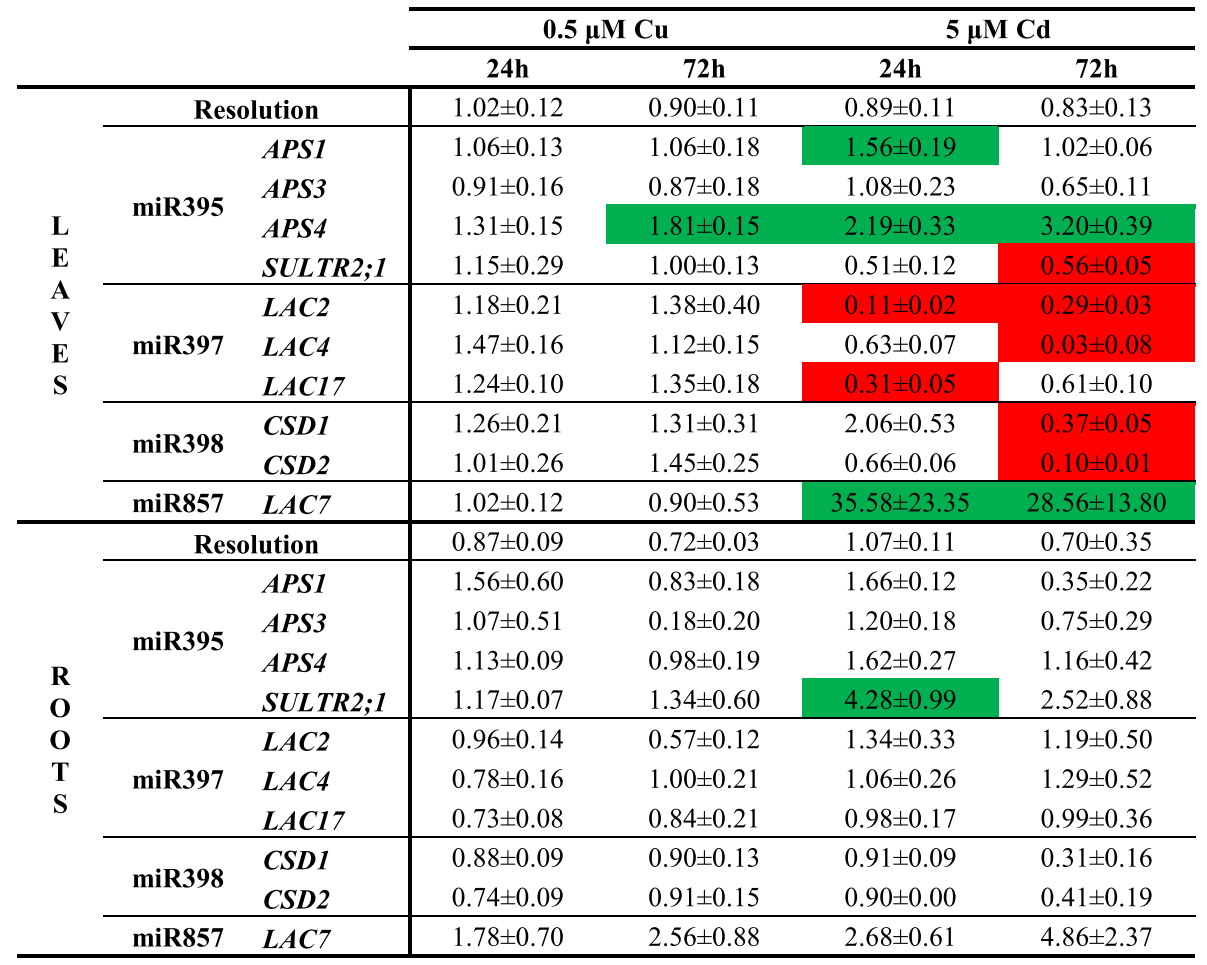


of its target ATP sulfurylase 4 (APS4) (Table 2). Also in the roots of $5 \mu \mathrm{M} \mathrm{Cd}$-exposed plants the only transcript level induced after $24 \mathrm{~h}$ exposure was from sulphate transporter 2;1 (SULTR2;1), a target of miR395 (Table 2). Nevertheless, in Cd-exposed leaves, multiple changes in expression levels of target genes were observed. An induced expression of the miR395 targets APS1 and APS4, and the miR857 target laccase 7 (LAC7) was found in Cd-exposed leaves, but these altered target expressions were not in accordance with the expression profiles of the miRNAs. Alternatively, the expression levels of $L A C 2$, $L A C 4$ and $L A C 17$ decreased in the leaves after $C d$ exposure, while the expression of the regulating miR397 increased. Similarly, the gene expression levels of the miR395 target SULTR2; 1 and the miR398 targets CSD1 and CSD2 decreased in the leaves after $72 \mathrm{~h} \mathrm{Cd}$ exposure (Table 2), while the expression of their regulating miRNAs increased (Table 1).

\section{The involvement of the transcription factor SPL7 in the $\mathrm{Cd}$ and $\mathrm{Cu}$ response}

The transcription factor SPL7, already known to be important for $\mathrm{Cu}$ homeostasis in plants [24], binds to GTAC motifs in the promoters of several miRNAs (cupro-miRNAs) thereby upregulating their expression [24]. A number of these cupro-miRNAs, namely miR397a, miR398b, miR398c and miR857 [24], were also $\mathrm{Cd}$ responsive (Table 1). Therefore, $\mathrm{Cu}$ and $\mathrm{Cd}$ responses were further investigated using an $s p l 7$ knockout mutant to define a possible role for SPL7 in these responses.

\section{Copper and $\mathrm{Cd}$ sensitivity of root growth in wild-type plants and the spl7 mutant}

Sensitivity of root growth of wild-type and spl7 mutants to excess $\mathrm{Cd}$ and $\mathrm{Cu}$ was tested in vertical agar plates. After germination on control plates, homogenous seedlings with a primary root length of approximately $2.5 \mathrm{~cm}$ and $2 \mathrm{~cm}$ for WT and spl7 mutant respectively were transferred to plates containing a concentration range of $\mathrm{Cd}$ or $\mathrm{Cu}$. The growth rate of the primary root was equal between both genotypes after transfer (data not shown). Therefore, the primary root growth after transfer was significantly lower in the spl7 mutant compared to WT plants under control conditions ( $2.48 \pm 0.05 \mathrm{~cm}$ and $3.04 \pm 0.12 \mathrm{~cm}$ respectively), and also the total lateral root length per unit primary root length was smaller in the mutant (Fig. 3). Exposure to $10 \mu \mathrm{M} \mathrm{Cu}$ significantly inhibited primary root length in both genotypes, but this inhibition was less pronounced in the spl7 mutants (Fig. 3a). On the other hand, total lateral root length per unit primary root length was lower after $3 \mu \mathrm{M} \mathrm{Cu}$ exposure in WT plants, whereas there was no effect in the spl7 mutant (Fig. 3b). After transfer to Cdcontaining plates, primary root growth and total lateral root length per unit primary root length were already significantly inhibited at $0.5 \mu \mathrm{M} \mathrm{Cd}$ in WT plants, while in the spl7 mutant inhibition was observed from $1.5 \mu \mathrm{M} \mathrm{Cd}$ exposure onwards (Fig. 3). Total lateral root length per unit primary root length, however, was significantly more inhibited at higher concentrations (1.5 and $5 \mu \mathrm{M} \mathrm{Cd})$ in the $s p l 7$ mutant compared to WT plants (Fig. 3b).

\section{Effect of $\mathrm{Cd}$ and excess $\mathrm{Cu}$ on fresh weight, lipid peroxidation and metal content}

In the following experiments, $\mathrm{Cu}$ concentrations were raised to $2 \mu \mathrm{M} \mathrm{Cu}$ since the $s p l 7$ mutant appeared to be less sensitive to $\mathrm{Cu}$ than WT plants. The effect of $2 \mu \mathrm{M}$ $\mathrm{Cu}$ and $5 \mu \mathrm{M} \mathrm{Cd}$ after $24 \mathrm{~h}$ and $72 \mathrm{~h}$ of exposure on fresh weight (FW) of both roots and leaves was determined (Fig. 4). After $24 \mathrm{~h}$ exposure, there was a significantly
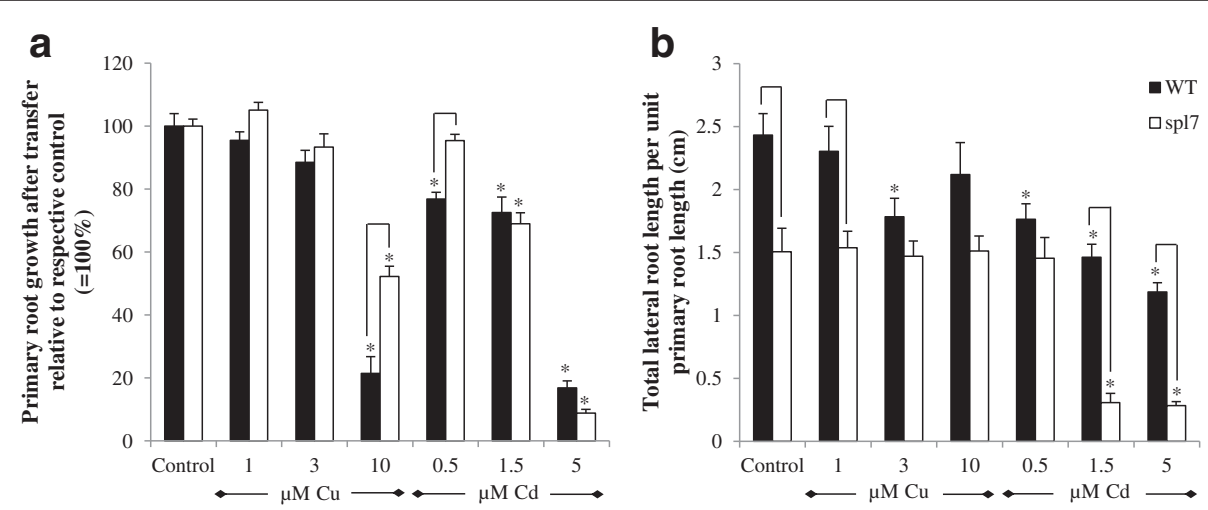

Fig. 3 Root growth parameters of $A$. thaliana wildtype and spl7 knockout plants. Primary root growth after transfer a is expressed relative to the control for each genotype and total lateral root length $\mathbf{b}$ is expressed per unit primary root length. Seven-days-old plants were exposed for another 7 days to 1,3 and $10 \mu \mathrm{M} \mathrm{CuSO}_{4}$ or $0.5,1.5$ and $5 \mu \mathrm{M} \mathrm{CdSO}_{4}$ or further grown under control conditions. Data are given as the mean \pm S.E. of at least 11 biological independent replicates. Significant differences $(P<0.05)$ after two-way ANOVA test (primary root growth) and Tukey correction or after non-parametrical ANOVA test (Kruskal-Wallis; lateral root length) and correction with pairwise Wilcoxon rank sum test are indicated as following: treatment difference with an asterisk $\left(^{*}\right)$ and genotype difference with connection lines 


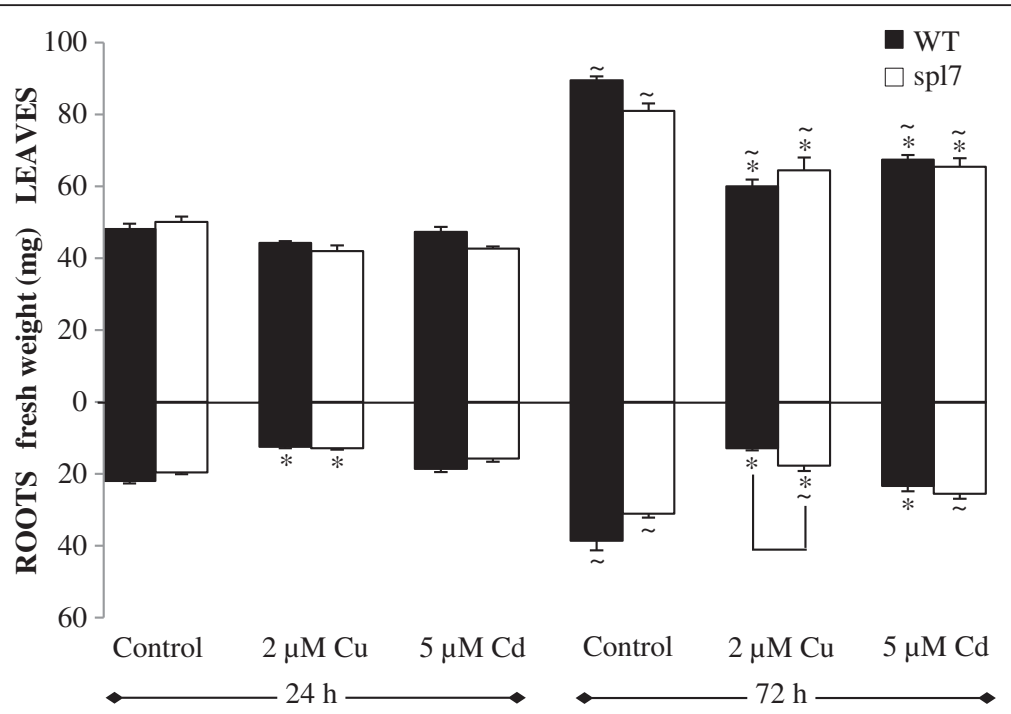

Fig. 4 Fresh weight in leaves and roots of $A$. thaliana wildtype and spl7 knockout plants. Nineteen-days-old plants were exposed for $24 \mathrm{~h}$ or $72 \mathrm{~h}$ to $2 \mu \mathrm{M} \mathrm{CuSO}_{4}, 5 \mu \mathrm{M} \mathrm{CdSO}_{4}$ or grown under control conditions. Data of the leaves (upper bars) and roots (lower bars) are given as the mean \pm S.E. of 5 biological independent replicates. Significant differences $(P<0.05)$ after three-way ANOVA test and Tukey correction are indicated as following: treatment difference with an asterisk $(*)$, time difference with a tilde $(\sim)$ and genotype difference with connection lines

decreased root FW after $2 \mu \mathrm{M} \mathrm{Cu}$ exposure in both genotypes. After $72 \mathrm{~h}$ exposure, the FW of roots and leaves in both genotypes was reduced after $\mathrm{Cu}$ and $\mathrm{Cd}$ exposure compared to control plants, except for Cd-exposed spl7 mutant roots. Whereas leaf FW of both genotypes increased over time in all conditions, this was also the case for root growth of the spl7 mutant, but not for $\mathrm{Cu}$ - and $\mathrm{Cd}$-exposed roots of WT plants, leading to a significant genotype difference in root FW after $72 \mathrm{~h} \mathrm{Cu}$ exposure (Fig. 4).

Whereas a significant increase in lipid peroxidation after $24 \mathrm{~h}$ exposure to $2 \mu \mathrm{M} \mathrm{Cu}$ was observed in both leaves and roots, $5 \mu \mathrm{M} \mathrm{Cd}$ exposure had no effect on lipid peroxidation. Under all conditions, there was no genotype difference in lipid peroxidation (Additional file 2: Figure S1).

The $\mathrm{Cu}$ and $\mathrm{Cd}$ content in roots and leaves of both genotypes after $24 \mathrm{~h}$ and $72 \mathrm{~h}$ exposure to $2 \mu \mathrm{M} \mathrm{Cu}$ and
$5 \mu \mathrm{M} \mathrm{Cd}$ were determined (Table 3). In roots and leaves of WT and spl7 mutant plants, $\mathrm{Cu}$ or $\mathrm{Cd}$ concentrations significantly increased after exposure to $2 \mu \mathrm{M} \mathrm{Cu}$ or $5 \mu \mathrm{M} \mathrm{Cd}$ respectively (Table 3 ). However, there were genotype differences in root metal content. In roots, spl7 mutant plants had a significantly lower $\mathrm{Cu}$ content as compared to WT plants after $24 \mathrm{~h} \mathrm{Cu}$ exposure, while their root $\mathrm{Cd}$ contents were significantly higher after $72 \mathrm{~h} \mathrm{Cd}$ exposure (Table 3). Although the $\mathrm{Cu}$ content increased in the roots of both genotypes after $72 \mathrm{~h} \mathrm{Cd}$ exposure in comparison with the control plants, the leaf $\mathrm{Cu}$ content was reduced in $s p l 7$ mutant plants and not in WT plants at this time point (Table 3). Alterations in metal uptake under control and exposed conditions also led to differences in the metal translocation factor (TF). The strong increase in root $\mathrm{Cu}$ content after $24 \mathrm{~h}$ and

Table 3 Copper and cadmium content in A. thaliana wildtype and spl7 knockout plants

\begin{tabular}{|c|c|c|c|c|c|c|}
\hline & & & \multicolumn{2}{|c|}{$24 \mathrm{~h}$} & \multicolumn{2}{|c|}{$72 \mathrm{~h}$} \\
\hline & & & WT & spl7 & WT & spl7 \\
\hline \multirow{6}{*}{$\mathrm{Cu}$} & \multirow{3}{*}{ leaves } & Control & $7.50 \pm 0.53^{\mathrm{abc}}$ & $6.53 \pm 0.37^{b c}$ & $8.95 \pm 0.81^{\text {abe }}$ & $9.76 \pm 0.66^{\text {ade }}$ \\
\hline & & $2 \mu \mathrm{MCu}$ & $12.43 \pm 0.32^{d}$ & $11.63 \pm 0.44^{\text {de }}$ & $16.70 \pm 1.33^{f}$ & $16.79 \pm 0.74^{f}$ \\
\hline & & $5 \mu \mathrm{M} \mathrm{Cd}$ & $6.31 \pm 0.21^{b c}$ & $4.93 \pm 0.74^{c}$ & $6.82 \pm 0.17^{\mathrm{abc}}$ & $4.64 \pm 0.48^{c}$ \\
\hline & \multirow{3}{*}{ roots } & Control & $25.00 \pm 2.81^{\mathrm{abc}}$ & $25.61 \pm 1.93^{\mathrm{abc}}$ & $18.91 \pm 1.18^{c}$ & $23.47 \pm 2.24^{b c}$ \\
\hline & & $2 \mu \mathrm{M} \mathrm{Cu}$ & $1069.45 \pm 30.28^{d}$ & $712.47 \pm 38.00^{e}$ & $943.04 \pm 43.13^{\mathrm{de}}$ & $854.71 \pm 50.80^{\text {de }}$ \\
\hline & & $5 \mu \mathrm{M} \mathrm{Cd}$ & $29.97 \pm 2.50^{\mathrm{ab}}$ & $27.38 \pm 2.18^{\mathrm{ab}}$ & $45.85 \pm 1.71^{f}$ & $34.45 \pm 2.04^{\mathrm{af}}$ \\
\hline \multirow{2}{*}{$\mathrm{Cd}$} & leaves & $5 \mu \mathrm{M} \mathrm{Cd}$ & $514.45 \pm 6.05^{a}$ & $699.38 \pm 156.61^{a}$ & $1831.70 \pm 53.69^{b}$ & $1549.40 \pm 151.09^{b}$ \\
\hline & roots & $5 \mu \mathrm{MCd}$ & $884.79 \pm 116.14^{\mathrm{a}}$ & $1282.86 \pm 152.62^{\mathrm{a}}$ & $2421.08 \pm 163.42^{b}$ & $3034.21 \pm 113.16^{C}$ \\
\hline
\end{tabular}

Nineteen-days-old plants were exposed for 24 or $72 \mathrm{~h}$ to $2 \mu \mathrm{M}$ CuSO4, $5 \mu \mathrm{M} \mathrm{CdSO} 4$ or grown under control conditions. Copper and Cd content (mg kg-1 DW-1) in roots and leaves were calculated. Data are given as the mean \pm S.E. of 5 biological independent replicates. Significant differences $(P<0.05)$ after three-way ANOVA test (Cu content) or two-way ANOVA test (Cd content; time/genotype) and Tukey correction are indicated with different small letters (per metal, per organ) 
$72 \mathrm{~h} \mathrm{Cu}$ exposure led to a significantly reduced $\mathrm{Cu} \mathrm{TF}$ under both conditions (Fig. 5a). Interestingly, also $\mathrm{Cd}$ exposure significantly reduced the $\mathrm{Cu}$ TF in both WT and $s p l 7$ mutant plants. Furthermore, the genotype difference in root $\mathrm{Cd}$ content after $72 \mathrm{~h} \mathrm{Cd}$ exposure also led to a genotype difference in the $\mathrm{Cd} \mathrm{TF}$ that was significantly lower in the spl7 mutant (Fig. 5b).

\section{Gene expression levels of SPL7-regulated Cd- and Cu- responsive (pri-)miRNAs and their targets}

The role of SPL7 in miRNA expression related to target gene expression during $\mathrm{Cd}$ and $\mathrm{Cu}$ stress was further explored with a gene expression analysis. Transcript levels of five pri-miRNAs (pri-miR397a, pri-miR398b, primiR398c, pri-miR408 and pri-miR857) and one gene (iron superoxide dismutase1, FSD1), all with GTAC motifs in their promoters, were determined in roots and

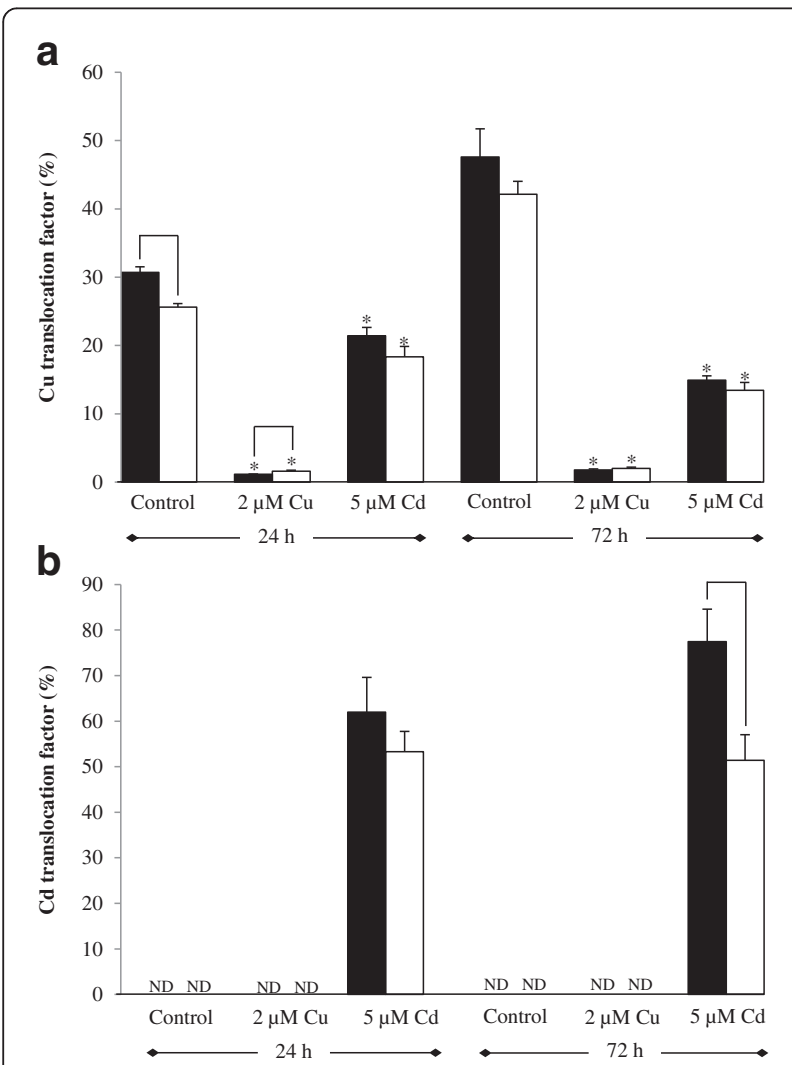

Fig. 5 The translocation factor of copper and cadmium from root to leaves. Nineteen-days-old A. thaliana wildtype and spl7 knockout plants were exposed for 24 or $72 \mathrm{~h}$ to $2 \mathrm{MM} \mathrm{CuSO}_{4}, 5 \mu \mathrm{M} \mathrm{CdSO}_{4}$ or grown under control conditions. The translocation factor (TF) of Cu (a) and $\mathrm{Cd}(\mathbf{b})$ were calculated as the percentage of the concentration in the leaves relative to the concentration in the roots. Data are given as the mean \pm S.E. of 5 biological independent replicates. Significant differences $(P<0.05)$ after non-parametrical ANOVA test (Kruskal-Wallis) and correction with pairwise Wilcoxon rank sum test are indicated as following: treatment difference with an asterisk $\left(^{*}\right)$ and genotype difference with connection lines leaves of WT and spl7 mutant plants exposed during $24 \mathrm{~h}$ to $2 \mu \mathrm{M} \mathrm{Cu}$ or $5 \mu \mathrm{M}$ Cd (Table 4). There was a clear genotype difference between WT and the spl7 mutant plants under control conditions. In the roots, the transcript level of FSD1 was reduced (not detectable) in the spl7 mutant compared to WT plants, while in the leaves the expression of pri-miR398b, pri-miR398c, primiR857 and FSD1 was significantly lower in the spl7 mutant (Table 4). For the WT genotype, similar $\mathrm{Cu}$ and $\mathrm{Cd}$ treatment differences were obtained as in the screening experiment (Table 1). In the roots, exposure to $2 \mu \mathrm{M} \mathrm{Cu}$ for $24 \mathrm{~h}$ significantly reduced the expression level of pri-miR398b and pri-miR398c in both genotypes and of FSD1 in WT plants. In the leaves, $\mathrm{Cu}$ exposure significantly lowered transcript levels of pri-miR398b, pri-miR398c, pri-miR857 and FSD1 in WT plants, while the low expression levels of the primiRNAs in the spl7 mutant under control conditions remained (Table 4). On the other hand, after $24 \mathrm{~h}$ exposure to $5 \mu \mathrm{M} \mathrm{Cd}$, there was a significantly upregulated expression in WT roots of FSD1 and all pri-miRNAs, except pri-miR408, and an upregulated expression in WT leaves of pri-miR398c and pri-miR857. These responses were absent in Cd-exposed spl7 mutants (Table 4).

The effects of $\mathrm{Cd}$ and $\mathrm{Cu}$ on the expression levels of the miRNA-regulated targets are given in Table 5 and are described per miRNA. Neither in roots nor in leaves of both genotypes significant changes were found in the expression levels of miR397 targets LAC2, LAC4 and $L A C 17$ under control conditions and after $\mathrm{Cu}$ exposure, except for a decreased transcript level of $L A C 4$ in the roots after $\mathrm{Cu}$ exposure. In addition, $L A C 2$ expression in the leaves was not detectable anymore after $5 \mu \mathrm{M} \mathrm{Cd}$ exposure in both genotypes (Table 5). Investigating the expression level of the miR857 target $L A C 7$ revealed that neither a genotype nor a treatment effect was observed in the roots. In the leaves however, $\mathrm{Cu}$ exposure significantly increased the expression of $L A C 7$ in the $s p l 7 \mathrm{mu}$ tant. Exposure to $\mathrm{Cd}$ significantly led to an upregulation of the pri-miR857 expression level in the leaves of the WT plants while this remained undetectable in the $s p l 7$ mutant (Table 4). However no significant changes were found for $L A C 7$ expression in WT plants, whereas a significant induction was observed in spl7 mutants (Table 5). Concerning the expression levels of the miR398 targets CSD1 and CSD2, no genotype effect was noticed in the roots under control conditions (Table 5). Although $\mathrm{Cu}$ exposure reduced the expression of pri-miR398b and $\mathrm{c}$ in both genotypes in the roots (Table 4 ), there was only a significant reduction present in the expression of CSD2 in the spl7 mutant (Table 5). There were no significant $\mathrm{Cd}$ treatment effects on the CSD transcript levels in the roots, which corresponds with the unaltered pri-miR398b and c expression levels in the $s p l 7$ mutant, but not with the $\mathrm{Cd}$ - 
Table 4 Gene expression levels of pri-miRNAs in A. thaliana wildtype and spl7 knockout plants. Nineteen-days-old plants were exposed for $24 \mathrm{~h}$ to $2 \mu \mathrm{M} \mathrm{CuSO}_{4}, 5 \mu \mathrm{M} \mathrm{CdSO}{ }_{4}$ or grown under control conditions. Data of the genotype effect of the spl7 mutant are given as the fold changes \pm S.E. of at least 3 biological independent replicates relative to WT plants (set at 1.00). Data of the treatment effect within each genotype are mean \pm S.E. of at least 3 biological replicates relative to its own control (set at 1.00). Significant differences $(P<0.05)$ after one-way (genotype effect) or two-way (treatment effect) ANOVA test and Tukey correction are indicated in color (upregulation, green; downregulation, red). (ND, not detected after 40 cycli)

\begin{tabular}{|c|c|c|c|c|c|c|c|}
\hline & \multirow{2}{*}{\multicolumn{2}{|c|}{$\begin{array}{c}\text { Genotype effect } \\
\text { under control conditions (WT set at } 1.00 \text { ) }\end{array}$}} & & \multicolumn{4}{|c|}{$\begin{array}{c}\text { Treatment effect } \\
\text { within each genotype (relative to its own control set at 1.00) } \\
\end{array}$} \\
\hline & & & & \multicolumn{2}{|c|}{$2 \mu \mathrm{M} \mathrm{Cu}$} & \multicolumn{2}{|c|}{$5 \mu \mathrm{M} \mathrm{Cd}$} \\
\hline & WT & spl7 & & WT & spl7 & WT & spl7 \\
\hline \multirow{7}{*}{$\begin{array}{l}\mathbf{L} \\
\mathbf{E} \\
\mathbf{A} \\
\mathbf{V} \\
\mathbf{E} \\
\mathbf{S}\end{array}$} & $1.00 \pm 0.22$ & $0.93 \pm 0.09$ & Resolution & $1.63 \pm 0.39$ & $0.98 \pm 0.01$ & $1.11 \pm 0.31$ & $0.90 \pm 0.15$ \\
\hline & $1.00 \pm 0.08$ & $1.09 \pm 0.39$ & pri-miR397a & $4.82 \pm 1.80$ & $2.18 \pm 0.68$ & $6.77 \pm 2.74$ & $1.12 \pm 0.35$ \\
\hline & $1.00 \pm 0.28$ & $0.05 \pm 0.01$ & pri-miR398b & $0.29 \pm 0.04$ & $1.56 \pm 0.26$ & $3.09 \pm 0.15$ & $0.99 \pm 0.18$ \\
\hline & $1.00 \pm 0.28$ & $0.05 \pm 0.01$ & pri-miR398c & $0.27 \pm 0.06$ & $1.41 \pm 0.32$ & $3.68 \pm 0.26$ & $1.36 \pm 0.16$ \\
\hline & $1.00 \pm 0.14$ & $0.39 \pm 0.01$ & pri-miR408 & $0.86 \pm 0.13$ & $1.06 \pm 0.18$ & $1.42 \pm 0.23$ & $1.14 \pm 0.26$ \\
\hline & $1.00 \pm 0.54$ & ND & pri-miR857 & ND & ND & $28.69 \pm 11.70$ & ND \\
\hline & $1.00 \pm 0.34$ & $1.8 \mathrm{E}-03 \pm 3.5 \mathrm{E}-04$ & FSD1 & $0.07 \pm 0.03$ & $0.81 \pm 0.17$ & $1.14 \pm 0.25$ & $0.45 \pm 0.16$ \\
\hline \multirow{7}{*}{$\begin{array}{l}\mathbf{R} \\
\mathbf{O} \\
\mathbf{O} \\
\mathbf{T} \\
\mathbf{S}\end{array}$} & $1.00 \pm 0.25$ & $0.57 \pm 0.08$ & Resolution & $1.38 \pm 0.15$ & $4.81 \pm 2.10$ & $0.76 \pm 0.33$ & $1.18 \pm 0.07$ \\
\hline & $1.00 \pm 0.20$ & $0.62 \pm 0.16$ & pri-miR397a & $1.05 \pm 0.28$ & $1.51 \pm 0.61$ & $6.02 \pm 1.85$ & $1.02 \pm 0.26$ \\
\hline & $1.00 \pm 0.08$ & $0.85 \pm 0.08$ & pri-miR398b & $0.19 \pm 0.01$ & $0.37 \pm 0.03$ & $3.95 \pm 0.53$ & $0.63 \pm 0.04$ \\
\hline & $1.00 \pm 0.13$ & $0.75 \pm 0.03$ & pri-miR398c & $0.25 \pm 0.03$ & $0.48 \pm 0.12$ & $5.34 \pm 0.77$ & $0.79 \pm 0.01$ \\
\hline & $1.00 \pm 0.31$ & $1.07 \pm 0.06$ & pri-miR408 & $0.70 \pm 0.19$ & $0.23 \pm 0.05$ & $1.25 \pm 0.36$ & $0.87 \pm 0.16$ \\
\hline & ND & ND & pri-miR857 & ND & ND & $1391.88 \pm 161.27$ & ND \\
\hline & $1.00 \pm 0.28$ & ND & FSD1 & $0.03 \pm 0.00$ & ND & $6.41 \pm 1.45$ & ND \\
\hline
\end{tabular}

induced expression of pri-miR398b and c in the WT roots. In the leaves, under control conditions the significantly lower transcript levels of pri-miR398b and c of the spl7 mutant compared to WT plants (Table 4) led to an increased expression of CSD2 in the spl7 mutant (Table 5). Furthermore, although in the WT leaves the expression of
pri-miR398b and c was significantly downregulated after $\mathrm{Cu}$ exposure and upregulated after $\mathrm{Cd}$ exposure (only primiR398c) and in the spl7 mutant the expression of primiR398b and c remained low after $\mathrm{Cu}$ and $\mathrm{Cd}$ exposure, there were no significant $\mathrm{Cu}$ and $\mathrm{Cd}$ treatment effects in the leaves on the expression of the CSDs.

Table 5 Expression levels of targets of SPL7 regulated miRNAs in A. thaliana wildtype and spl7 knockout plants. Nineteen-days-old plants were exposed for $24 \mathrm{~h}$ to $2 \mathrm{\mu M} \mathrm{CuSO}_{4}, 5 \mu \mathrm{M} \mathrm{CdSO}_{4}$ or grown under control conditions. Data of the genotype effect of the spl7 mutant are given as the fold changes \pm S.E. of at least 3 biological independent replicates relative to WT plants (set at 1.00). Data of the treatment effect (within each genotype) are mean \pm S.E. of at least 3 biological replicates relative to its own control (set at 1.00). Significant differences $(P<0.05)$ after one-way (genotype effect) or two-way (treatment effect) ANOVA test and Tukey correction are indicated in color (upregulation, green; downregulation, red). (ND, not detected after 40 cycli)

Genotype effect
under control conditions (WT set at 1.00)

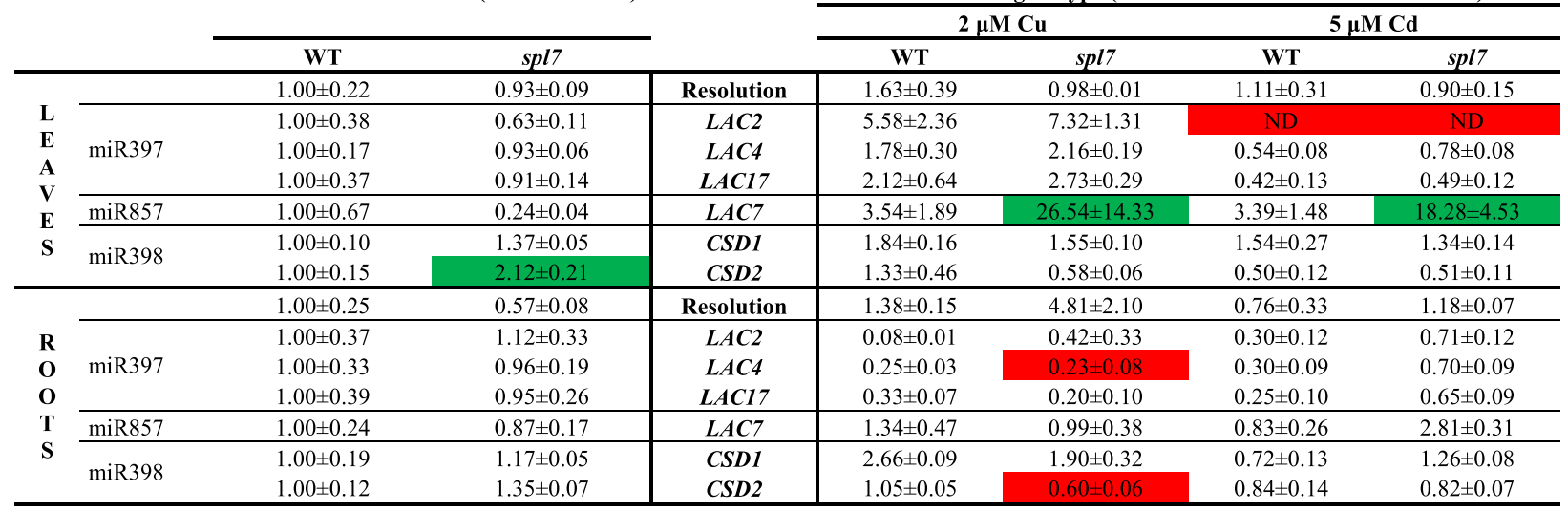


The impact of adding additional $\mathrm{Cu}$ to $\mathrm{Cd}$-exposed plants Since SPL7 is involved in the $\mathrm{Cd}$ response and $\mathrm{Cu}$ homeostasis is disturbed after $\mathrm{Cd}$ exposure, knowing the impact of adjustments to external $\mathrm{Cu}$ concentrations in combination with $\mathrm{Cd}$ exposure will provide more insights in the $\mathrm{Cd}$-induced $\mathrm{Cu}$ deficiency responses. Therefore, WT plants were simultaneously exposed to $5 \mu \mathrm{M} \mathrm{Cd}$ and increasing concentrations of $\mathrm{Cu}(0.5,1$ or $2 \mu \mathrm{M} \mathrm{Cu}$ additionally added to the Hoagland solution) for $72 \mathrm{~h}$ whereafter metal content and gene expression analyses were performed.

\section{Additional $\mathrm{Cu}$ restores $\mathrm{Cu}$ levels and reduces $\mathrm{Cd}$ levels in leaves of Cd-exposed plants}

Exposure of plants to $5 \mu \mathrm{M} \mathrm{Cd}$ resulted in decreased $\mathrm{Cu}$ levels in the leaves, while after exposure to $\mathrm{Cd}$ in combination with extra $\mathrm{Cu}(1$ and $2 \mu \mathrm{M} \mathrm{Cu})$ there was no difference in leaf $\mathrm{Cu}$ content compared to control plants (Fig. 6a). In the roots, $\mathrm{Cu}$ levels were increased after exposure to $5 \mu \mathrm{M} \mathrm{Cd}$ and adding extra $\mathrm{Cu}$ to $\mathrm{Cd}$-exposed plants increased $\mathrm{Cu}$ levels even more (Fig. 6c). On the contrary, the addition of extra $\mathrm{Cu}$ significantly reduced $\mathrm{Cd}$ content in leaves and roots compared to exposure to Cd only (Fig. 6b and d).

\section{The $\mathrm{Cd}$-induced $\mathrm{Cu}$ deficiency response disappears with supplemental $\mathrm{Cu}$}

The effect of adding supplemental $\mathrm{Cu}$ to $\mathrm{Cd}$-exposed plants was further explored with a gene expression analysis in the leaves. The transcript level of FSD1 was induced in the leaves of plants grown under $\mathrm{Cu}$ deficiency or after exposure to $5 \mu \mathrm{M} \mathrm{Cd}$. However, this induction disappeared in plants exposed to $5 \mu \mathrm{M} \mathrm{Cd}$ in combination with extra $\mathrm{Cu}$ (0.5, 1 and $2 \mu \mathrm{M})$ (Fig. 7). In general, the same response was observed for the transcript levels of all other measured SPL7-regulated pri-miRNAs, mature miRNAs (miR397a, $\mathrm{miR} 398 \mathrm{~b} / \mathrm{c}, \mathrm{miR} 857$ ) and the gene COPT2 (Table 6). Whereas the increased expression after $\mathrm{Cd}$ exposure did not always completely disappear when extra $\mathrm{Cu}$ was added, most transcript levels significantly decreased. Furthermore,
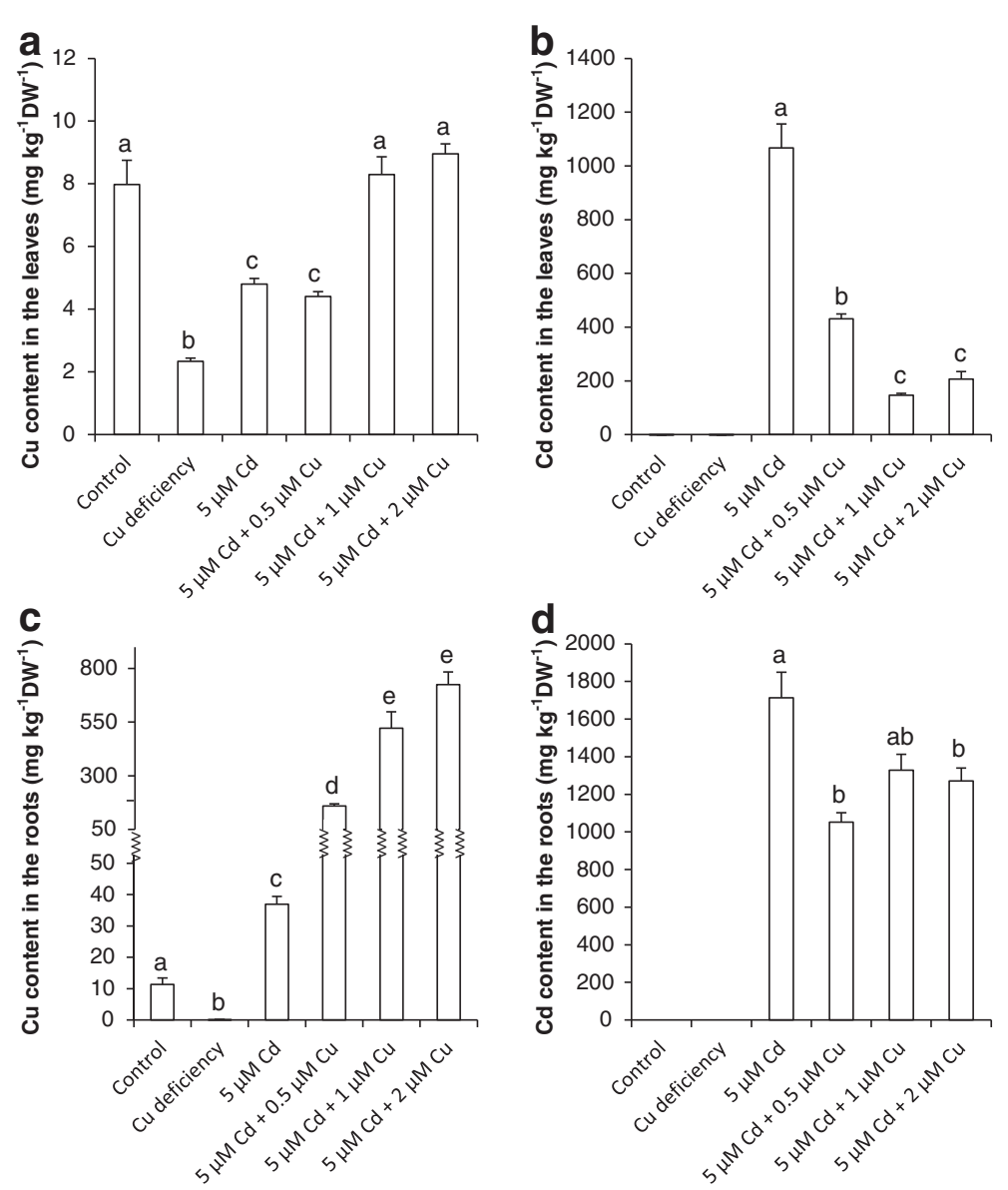

Fig. 6 Copper and Cd content in leaves and roots of wildtype plants. Nineteen-days-old plants were further grown under control conditions or Cu deficiency, or were exposed to $5 \mu \mathrm{M}$ Cd and supplemented with extra $\mathrm{Cu}(0,0.5,1$ or $2 \mu \mathrm{M}$ Cu extra compared to control Hoagland solution) for $72 \mathrm{~h}$. Copper and $\mathrm{Cd}$ contents were calculated in $\mathrm{mg}$ per $\mathrm{kg}$ dry weight $\left(\mathrm{mg} \mathrm{kg}^{-1} \mathrm{DW}^{-1}\right)$. Data are mean \pm S.E. of 6 biological replicates. Significant differences $(P<0.05)$ after one-way ANOVA test and Tukey correction are indicated with different letters 


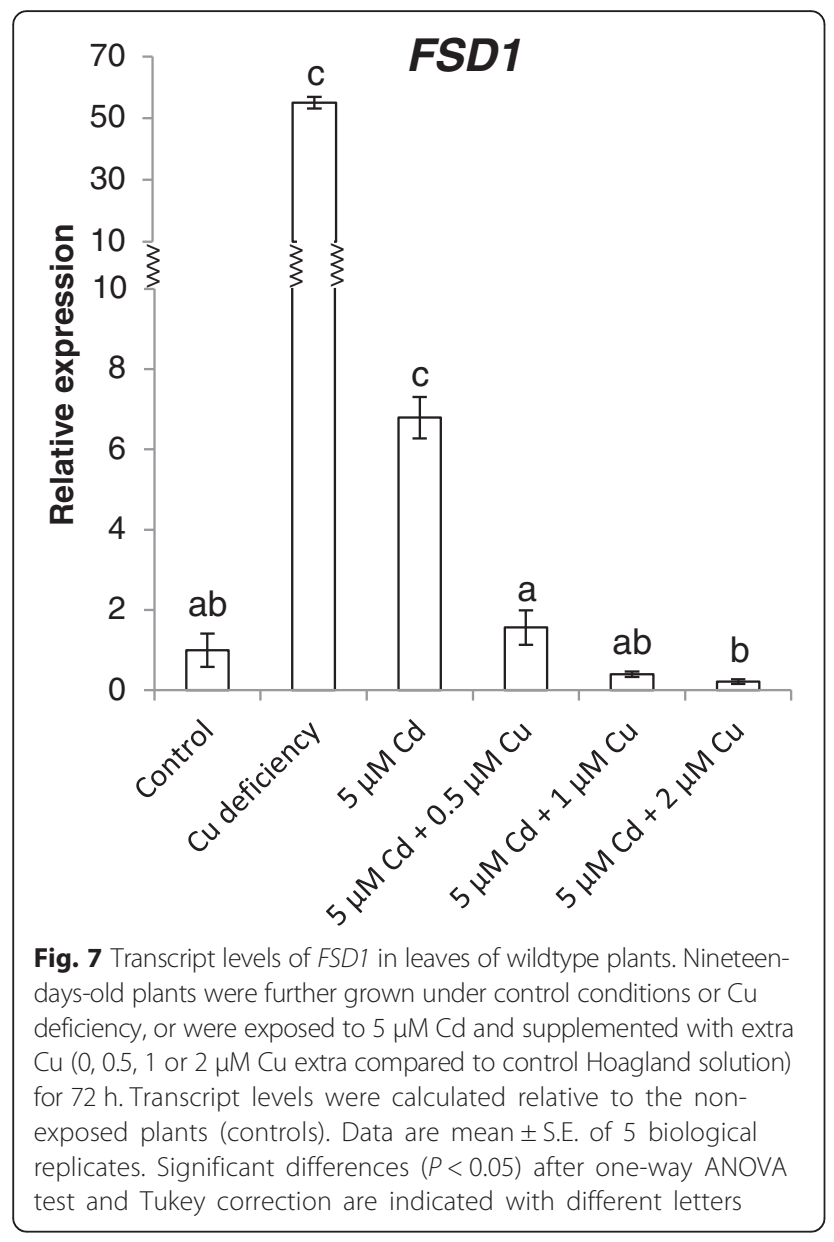

the expression of CSD1 and CSD2 reduced in $\mathrm{Cu}$ deficient and $\mathrm{Cd}$-exposed plants, while in the combined application of $\mathrm{Cd}$ and supplemental $\mathrm{Cu}$, there was no difference in CSD1 and CSD2 transcript levels as compared to control plants (Table 6).

\section{Discussion}

Plant growth and development is challenged due to the occurrence of several environmental stressors, including elevated metal concentrations. Therefore, an appropriate regulation of stress responses is of major importance. MiRNAs have a regulatory role in numerous stresses, including metal stress [15]. High-throughput expression profiling of plants exposed to metals have identified several metal-responsive miRNAs [19, 20, 26-30], however the regulation of these miRNAs and the precise role of these miRNAs and their targets in metal responses remain to be explored. Therefore, identifying $\mathrm{Cu}$ - and $\mathrm{Cd}$ responsive miRNAs in $A$. thaliana and their regulation after $\mathrm{Cu}$ and $\mathrm{Cd}$ exposure represent important research questions.

To identify $\mathrm{Cu}$ - and $\mathrm{Cd}$-responsive miRNAs in $A$. thaliana, we exposed 19-days-old plants for 2, 24 and $72 \mathrm{~h}$ to $0.5 \mu \mathrm{M} \mathrm{Cu}, 5 \mu \mathrm{M} \mathrm{Cd}$ or grew them under control conditions. The applied metal concentrations in our study are sublethal and based on the concentrations found in pore water of sandy soils in polluted areas of Belgium [31-33]. Whether the applied metal concentrations were toxic was verified at the morphological level [impaired root development (Fig. 1)] and at the cellular level [induced lipid peroxidation (Fig. 2)]. These

Table 6 Gene expression levels of SPL7-regulated genes and targets of miR398b/c in the leaves of A. thaliana. Nineteen-days-old plants were exposed for $72 \mathrm{~h}$ to $5 \mathrm{\mu M} \mathrm{CdSO}_{4}$ with $0,0.5,1$ or $2 \mu \mathrm{M} \mathrm{CuSO} \mathrm{M}_{4}$ extra, or grown under Cu deficiency from germination on or under control conditions. Transcript levels were calculated relative to the non-exposed plants. Data are mean \pm S.E. of at least 5 biological replicates. Significant differences $(P<0.05)$ after one-way ANOVA test and Tukey correction are indicated with colour shading: red for reduction compared to control, dark green for induction compared to control and light green for induction compared to control but reduction compared to $5 \mu \mathrm{M} C d$

\begin{tabular}{|c|c|c|c|c|c|c|}
\hline & Control & $\mathrm{Cu}$ deficiency & $5 \mu \mathrm{M} \mathrm{Cd}$ & $\begin{array}{l}5 \mu \mathrm{M} \mathrm{Cd}+ \\
0.5 \mu \mathrm{M} \mathrm{Cu}\end{array}$ & $\begin{array}{c}5 \mu \mathrm{MCd}+ \\
1 \mu \mathrm{MCu}\end{array}$ & $\begin{array}{c}5 \mu \mathrm{M} \mathrm{Cd}+ \\
2 \mu \mathrm{M} \mathrm{Cu} \\
\end{array}$ \\
\hline Resolution mature miRNAs & $1.00 \pm 0.18$ & $1.59 \pm 0.23$ & $1.20 \pm 0.18$ & $1.21 \pm 0.26$ & $1.37 \pm 0.39$ & $1.14 \pm$ \\
\hline Resolution other genes & $1.00 \pm 0.21$ & $1.65 \pm 0.84$ & $0.51 \pm 0.05$ & $0.90 \pm 0.30$ & $1.41 \pm 0.73$ & $0.91 \pm$ \\
\hline \multicolumn{7}{|l|}{ SPL7-regulated genes } \\
\hline pri-miR397a & $1.00 \pm 0.28$ & $10.75 \pm 1.31$ & $5.08 \pm 1.15$ & $0.78 \pm 0.16$ & $0.51 \pm 0.10$ & $0.35 \pm 0.06$ \\
\hline miR397a & $1.00 \pm 0.40$ & $32.60 \pm 10.99$ & $5.72 \pm 1.92$ & $0.46 \pm 0.36$ & $0.72 \pm 0.29$ & $1.30 \pm 0.73$ \\
\hline pri-miR398b & $1.00 \pm 0.35$ & $12.96 \pm 0.56$ & $9.21 \pm 1.23$ & $1.32 \pm 0.17$ & $0.47 \pm 0.09$ & $0.28 \pm 0.04$ \\
\hline pri-miR398c & $1.00 \pm 0.12$ & $122.12 \pm 8.23$ & $96.26 \pm 8.02$ & $7.07 \pm 1.25$ & $1.11 \pm 0.35$ & $0.33 \pm 0.11$ \\
\hline $\mathrm{miR398b} / \mathrm{c}$ & $1.00 \pm 0.67$ & $15.16 \pm 2.18$ & $4.78 \pm 0.73$ & $0.55 \pm 0.05$ & $0.18 \pm 0.04$ & $0.06 \pm 0.01$ \\
\hline pri-miR857 & ND & $402.07 \pm 23.00$ & $151.94 \pm 35.30$ & $4.96 \pm 1.43$ & ND & ND \\
\hline $\operatorname{miR857}$ & $1.00 \pm 0.35$ & $642.46 \pm 78.01$ & $45.09 \pm 15.28$ & $6.56 \pm 2.37$ & $8.87 \pm 3.70$ & $8.44 \pm 4.20$ \\
\hline COPT2 & $1.00 \pm 0.19$ & $5.03 \pm 0.31$ & $4.84 \pm 0.21$ & $2.23 \pm 0.16$ & $1.44 \pm 0.08$ & $1.30 \pm 0.10$ \\
\hline FSD1 & $1.00 \pm 0.41$ & $55.06 \pm 1.89$ & $6.79 \pm 0.51$ & $1.57 \pm 0.43$ & $0.40 \pm 0.07$ & $0.22 \pm 0.05$ \\
\hline \multicolumn{7}{|l|}{ Targets of miR398b/c } \\
\hline CSD1 & $1.00 \pm 0.14$ & $0.08 \pm 0.01$ & $0.34 \pm 0.07$ & $0.87 \pm 0.03$ & $1.25 \pm 0.08$ & $1.32 \pm 0.07$ \\
\hline CSD2 & $1.00 \pm 0.10$ & $0.07 \pm 0.00$ & $0.15 \pm 0.04$ & $0.90 \pm 0.04$ & $0.79 \pm 0.06$ & $0.93 \pm 0.05$ \\
\hline
\end{tabular}


parameters were previously shown to be affected upon $\mathrm{Cd}$ and $\mathrm{Cu}$ exposure [22, 34-39].

In order to clarify whether $\mathrm{Cu}$ - and $\mathrm{Cd}$-induced responses are dependent on miRNAs, we analyzed the expression profile of 180 pri-miRNAs in $\mathrm{Cu}$ - and $\mathrm{Cd}$-exposed roots and leaves. Pant et al. [14] validated the use of a primiRNA profiling platform as a useful screening tool. Although it is recently demonstrated that the level of primiRNAs not always reflects the level of its mature miRNA [40], other studies have shown the correlation between primiRNA and mature miRNA levels [11, 14] as was also observed for the majority of the analysed miRNAs in our study (Table 6). Until lately, miR398 was the only miRNA family that was known to be involved in $\mathrm{Cu}$ and $\mathrm{Cd}$ stress in A. thaliana [21, 22]. But recently Barciszewska-Pacak et al. [40] identified more than 40 Arabidopsis pri-miRNAs responsive to (among others) $\mathrm{Cd}$ and $\mathrm{Cu}$ excess using an RT-qPCR mirEX platform. The $\mathrm{Cd}$ and $\mathrm{Cu}$ responsive primiRNAs that we identified in our experimental setup (Table 1), showed no altered expression in their study, except for pri-miR398a/b/c after $\mathrm{Cu}$ exposure, which could be due to the different experimental setups. BarciszewskaPacak et al. [40] screened the pri-miRNA expression in leaves of plants grown on $0.8 \%$ agar 1/2MS plates exposed for $24 \mathrm{~h}$ to $10 \mu \mathrm{M} \mathrm{Cu}$ and $10 \mu \mathrm{M} \mathrm{Cd}$ [40], while we used both leaf and root samples of plants grown in hydroponic culture exposed during 2, 24 and $72 \mathrm{~h}$. Although fast alterations in miRNA expression levels after $0.5 \mu \mathrm{M} \mathrm{Cu}$ and $5 \mu \mathrm{M}$ Cd were observed in our study, a negative correlation with the transcript levels of their targets was not always seen, especially not in the $\mathrm{Cu}$-exposed plants (Table 2). However, Cd exposure resulted in the leaves in induced expression levels of miR395, miR397 and miR398 and this led to reduced transcript levels of their targets SULTR2;1, LAC2, LAC4 and LAC17, and CSD1 and CSD2 (Tables 1 and 2). Cuypers et al. [22] already demonstrated an upregulation of miR398b together with a downregulation of CSD1 and CSD2 in A. thaliana after $24 \mathrm{~h}$ exposure to $5 \mu \mathrm{M} \mathrm{Cd}$. The negative correlations between Cd-responsive miRNAs and their targets show the importance of miRNAs in regulatory networks.

In this study, we exposed plants to $\mathrm{Cu}$ and $\mathrm{Cd}$, two metals that have different physico-chemical properties, i.e. $\mathrm{Cu}$ is an essential nutrient and redox-active whereas $\mathrm{Cd}$ is nonessential and not redox-active. Striking is the opposite regulation after $\mathrm{Cu}$ and $\mathrm{Cd}$ exposure of $\mathrm{miR} 398 \mathrm{~b} / \mathrm{c}$ in the leaves and the specific Cd-responsive miRNAs, namely miR157a, miR167c, miR397a and miR857 that were not (or very low) expressed under control conditions or after $\mathrm{Cu}$ exposure (Table 1). Some of these miRNAs, more specifically miR397a, miR398b/c and miR857 all have several GTAC motifs in their promoter regions, which are binding places for the transcription factor SQUAMOSA promoter binding protein-like7
(SPL7) [24]. SPL7 is assumed to be the key regulator of $\mathrm{Cu}$ homeostasis. Under $\mathrm{Cu}$ deficiency, it activates transcription of the so-called cupro-miRNAs (miR397, miR398b/c, miR408 and miR857) targeting $\mathrm{Cu}$-containing proteins, i.e. laccases and $\mathrm{Cu} / \mathrm{Zn}$ superoxide dismutases [24]. Additionally, GTAC motifs are present in the promoters of several $\mathrm{Cu}$-transporters, such as COPT1, COPT2 and COPT6, and a copper chaperone $\mathrm{CCH}$ and the expression of all these genes is increased under $\mathrm{Cu}$ deficiency through the action of SPL7 [41]. Because of the SPL7-dependent decrease of non-essential or replaceable $\mathrm{Cu}$-containing proteins and the SPL7-dependent increase of $\mathrm{Cu}$ transporters under $\mathrm{Cu}$ deficiency, it is suggested that the limited available $\mathrm{Cu}$ is preferred for plastocyanin in photosynthesis and $\mathrm{Cu}$ uptake in the roots is stimulated [24]. In general, after $\mathrm{Cu}$ excess the expression of the cupro-miRNAs (miR397a, miR398b/c and miR857) were decreased or not detectable at all (Table 1). In addition, exposure to $\mathrm{Cd}$ increased the transcript levels of these cupro-miRNAs (Table 1). The induced expression of miR398b/c after Cd exposure was already demonstrated in previous studies [22, 41], but this regulation was not yet seen for miR397a and miR857 in $A$. thaliana (Table 1).

Gayomba et al. [41] demonstrated that SPL7 is involved in the Cd-induced increase of miR398, as well as in the upregulated expression of FSD1 and COPT1/2/6. Therefore, we wanted to confirm this SPL7 dependency of the $\mathrm{Cd}$-induced $\mathrm{Cu}$ deficiency response in our experimental setup with expansion of the data to all cupro-miRNAs and their targets. Furthermore, we were also interested in the possible involvement of SPL7 in the response to $\mathrm{Cu}$ excess. To analyse this, we used an spl7 knockout mutant. The $\mathrm{Cu}$ and $\mathrm{Cd}$ sensitivity of the $s p l 7$ mutant was determined based on root growth of plants grown on vertical agar plates and exposed to a range of $\mathrm{Cu}$ and $\mathrm{Cd}$ concentrations. On one hand, primary root growth (Fig. 3a), lateral root length per unit primary root length (Fig. 3b) and root FW (Fig. 4) was less or not diminished in $\mathrm{Cu}$ exposed spl7 mutants compared to WT plants. On the other hand, exposure to $\mathrm{Cd}$ reduced primary root growth and lateral root length (Fig. 3) in both genotypes, however, lateral root length per unit primary root length decreased tremendously more in the $s p l 7$ mutant. Therefore we can conclude that the spl7 mutant is less sensitive to excess $\mathrm{Cu}$ and more sensitive to $\mathrm{Cd}$ toxicity compared to the WT plants.

We wanted to confirm and expand our knowledge about the involvement of SPL7 in Cd toxicity stress responses and to determine whether SPL7 also plays a role in $\mathrm{Cu}$ toxicity stress responses. Therefore, gene expression levels of cupro-pri-miRNAs and their targets were measured in hydroponically grown WT and spl7 mutant plants after exposure to $2 \mu \mathrm{M} \mathrm{Cu}$ and $5 \mu \mathrm{M} \mathrm{Cd}$ for $24 \mathrm{~h}$. Since the spl7 mutant is less sensitive to $\mathrm{Cu}$ than WT 
plants, $\mathrm{Cu}$ concentrations were elevated to $2 \mu \mathrm{M} \mathrm{Cu}$, which is still a sublethal environmentally realistic concentration. Although SPL7 has been put forward as the major regulator of $\mathrm{Cu}$ deficiency and a central regulator of $\mathrm{Cu}$ homeostasis [24], SPL7 also plays a role under control conditions since the total knockout of SPL7 in the $s p l 7$ mutant led to a downregulation of several miRNAs (pri-miR398b and c, pri-miR408 and pri-miR857) (Table 4). This is conform with the findings of Gayomba et al. [41] where transcript levels of other genes with a GTAC-containing promoter (COPT2, COPT6, FSD1 and miR398) were reduced in the spl7 mutant. We found that exposure to excess $\mathrm{Cu}$ in general downregulates the cupro-miRNAs in WT plants and that the already very low expression of these cupro-miRNAs in the spl7 mutant remained low after excess $\mathrm{Cu}$ (Table 4, Fig. 8). Previous studies also demonstrated the downregulation of miR398 after $\mathrm{Cu}$ exposure in A. thaliana [21, 22]. This response to $\mathrm{Cu}$ toxicity is comprehensible since the opposite is expected compared to $\mathrm{Cu}$ deficiency, with no activation of SPL7 and hence, no induction of transcription of these miRNAs and genes (Fig. 8). In contrast, while $\mathrm{Cu}$ toxicity generally resulted in a downregulation of these cupro-miRNAs, Cd toxicity induced the transcript levels of miR397a, miR398b/c, miR857 and FSD1 (Table 4, Fig. 8). However, this induced expression of cupro-miRNAs and FSD1 in WT plants after Cd exposure was totally abolished in the spl7 mutant (Table 4) just like it is demonstrated for the expression of COPT1/ $2 / 6$ [41]. With these findings we confirm that the $\mathrm{Cd}$ induced $\mathrm{Cu}$ deficiency response depends on SPL7 [41] (Fig. 8).

In order to verify whether the targets of the SPL7regulated miRNAs are also under the control of SPL7

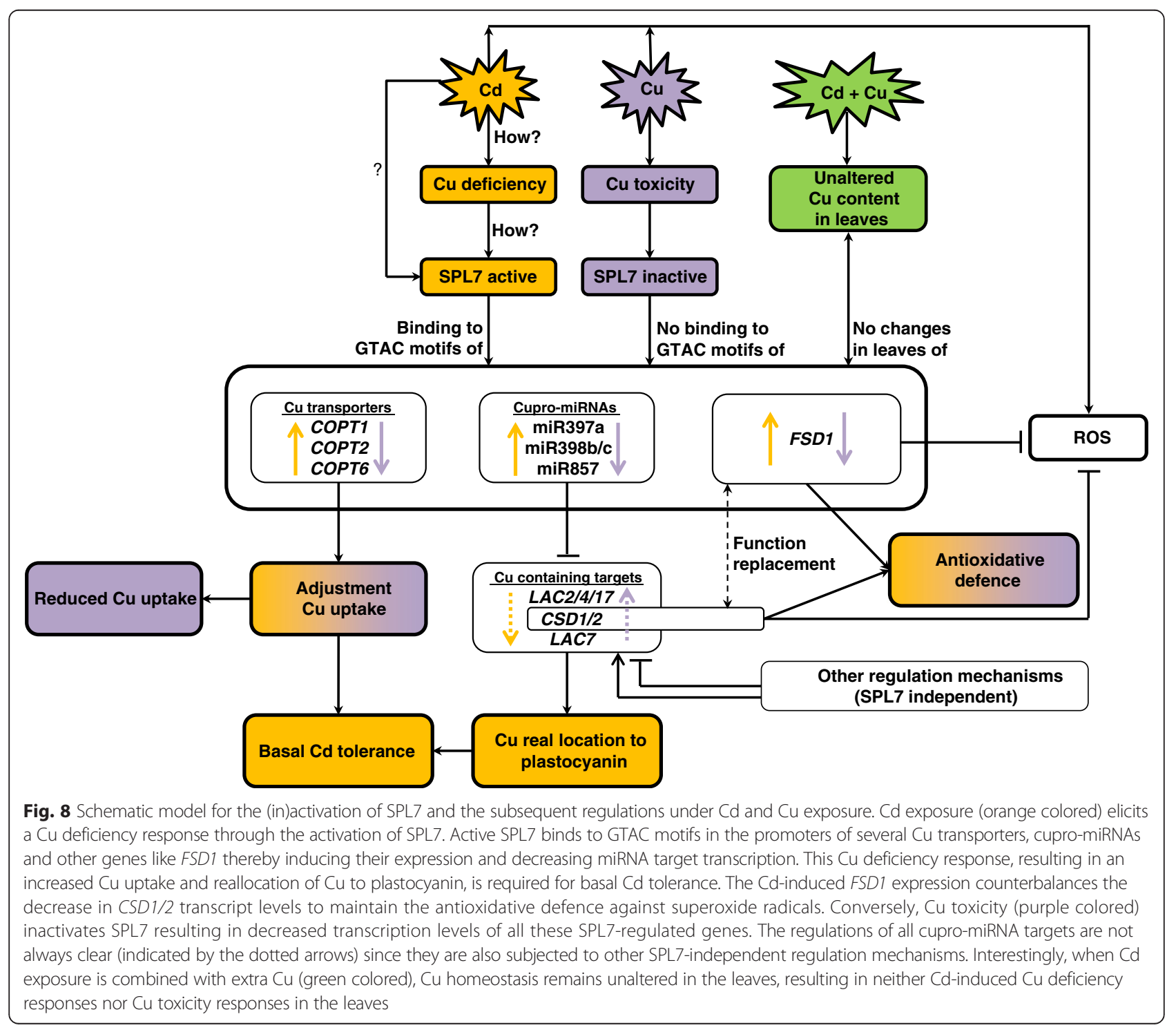


after $\mathrm{Cu}$ and $\mathrm{Cd}$ exposure, target gene expression levels were measured. Clear up- or downregulation of the cupro-miRNAs (Table 4) is not always leading to alterations in target expression levels (Table 5), since the observed target gene transcript levels are a result of both, transcriptional activity regulated by other transcription factors and the SPL7-dependent miRNA-mediated posttranscriptional breakdown (Fig. 8). Multiple studies describe the reduced expression of $\mathrm{miR} 398 \mathrm{~b} / \mathrm{c}$ and induction of CSD transcript levels after exposure to excess $\mathrm{Cu}$ $[21,22]$. This is in accordance with our findings where a downregulation of $\mathrm{miR} 398 \mathrm{~b} / \mathrm{c}$ and a maintained or small upregulation of CSDs were seen (Tables 4 and 5). In addition, it has been shown that excess $\mathrm{Cu}$ leads to an elevated production of reactive oxygen species (ROS) to which plants have to defend themselves [22, 34, 42]. Therefore, the putatively SPL7-dependent miR398mediated maintenance of CSD transcript levels can be a first-line defence against $\mathrm{Cu}$-induced oxidative stress. Nevertheless, Cd also induces oxidative stress ([43] and references therein), but compared to the $\mathrm{Cu}$ toxicity response, CSD transcript levels were decreased in our study (Table 2). However, alternatively Cd induced FSD1 expression (Table 4), also regulated by SPL7, to maintain the SOD capacity (Fig. 8).

It is known that $\mathrm{Cd}$ competes with other essential elements for cellular uptake sites and for binding sites in metalloenzymes, thereby disturbing the homeostasis of these elements [42, 44]. For example, Yoshihara et al. [45] and $\mathrm{Xu}$ et al. [46] demonstrated the disturbance of the iron homeostasis after $\mathrm{Cd}$ exposure at morphological and molecular level. In this regard, Cd possibly also interferes with $\mathrm{Cu}$ homeostasis (Fig. 8) as shown by the higher $\mathrm{Cu}$ content in the roots after exposure to $\mathrm{Cd}$ (Table 3 and Fig. 6c) and by the induction of several $\mathrm{Cu}$ transporters (Table 6 and Fig. 8) [41]. This disturbance in $\mathrm{Cu}$ homeostasis, causing $\mathrm{Cu}$ deficiency, possibly can result in the activation of SPL7, the major regulator for $\mathrm{Cu}$ homeostasis in $A$. thaliana. This subsequently results into upregulations of the $\mathrm{Cu}$ transporters and cupromiRNAs and hence downregulations of their targets as seen in this study (Tables 4,5,6 and Fig. 8). In addition, Gayomba et al. [41] stated that this SPL7-dependent $\mathrm{Cu}$ deficiency response, i.e. $\mathrm{Cu}$ uptake and reallocation, is required for basal Cd tolerance in $A$. thaliana.

However, how SPL7 is activated and how Cd induces the $\mathrm{Cu}$ deficiency response is still unknown. Recently, a working model for the regulation of SPL7 function was reported [47] as well as several scenarios for the link between Cd and SPL7 activation proposed [41]. On one hand it is proposed that $\mathrm{Cd}$ could directly interact with SPL7 or on the other hand could alter the cellular $\mathrm{Cu}$ availability and hence affect SPL7 activation [41]. Therefore, in a subsequent experiment, extra $\mathrm{Cu}$ was supplemented (0.5, 1 and $2 \mu \mathrm{M} \mathrm{Cu}$ ) to Cd-exposed plants and the $\mathrm{Cd}$-induced $\mathrm{Cu}$ deficiency responses were analysed. The decreased $\mathrm{Cu}$ content in leaves of $\mathrm{Cd}$ exposed plants (Fig. 6a) [41] restored to control level when extra $\mathrm{Cu}$ was added, while the opposite was seen for Cd (Fig. 6b). In addition, at the transcript level, the observed $\mathrm{Cu}$ deficiency response after $\mathrm{Cd}$ exposure disappeared when extra $\mathrm{Cu}$ was added (Table 6). Taken together, these data support our hypothesis that adding extra $\mathrm{Cu}$ to $\mathrm{Cd}$-exposed plants restores $\mathrm{Cu}$ levels in leaves resulting in the disappearance of the $\mathrm{Cu}$ deficiency response. Thus, $\mathrm{Cd}$ possibly provokes $\mathrm{Cu}$ deficiency, thereby activating SPL7 and inducing subsequently the $\mathrm{Cu}$ deficiency response (Fig. 8). However, whether the disappearance of the $\mathrm{Cd}$-induced $\mathrm{Cu}$ deficiency response after adding extra $\mathrm{Cu}$ is due to restored $\mathrm{Cu}$ levels or due to reduced $\mathrm{Cd}$ levels should be further investigated.

\section{Conclusions}

In this study, we identified several miRNAs that are involved in responses to $\mathrm{Cu}$ and $\mathrm{Cd}$ excess. Copper and $\mathrm{Cd}$ are physico-chemically different metals and have an opposite effect on the expression of some $\mathrm{Cu}$ transporters, miRNAs (miR397a, miR398b/c, miR857) and the gene FSD1 (Fig. 8), that all have GTAC binding sites for the transcription factor SPL7 in their promoter. SPL7 seems to be a shared component between both the $\mathrm{Cu}$ toxicity and the $\mathrm{Cd}$ toxicity response, yet oppositely regulated, that is inactivated after $\mathrm{Cu}$ exposure and activated after Cd exposure (Fig. 8). Since SPL7 is the key regulator of $\mathrm{Cu}$ homeostasis, and $\mathrm{Cd}$ affects the $\mathrm{Cu}$ content in the roots and the $\mathrm{Cu}$ translocation to the shoots, we hypothesize that the involvement of SPL7 in the Cd response is possibly due to a $\mathrm{Cd}$-induced $\mathrm{Cu}$ deficiency (Fig. 8). How $\mathrm{Cd}$ induces $\mathrm{Cu}$ deficiency and how SPL7 is activated remain interesting research topics that require further investigation.

\section{Methods}

\section{Plant culture, exposure and harvest}

The spl7 knockout mutant $A$. thaliana line (Col-0 background; SALK_125385C; Alonso et al. [48]) was obtained from the European Arabidopsis Stock Centre (uNASC) and was confirmed by PCR to be a homozygous T-DNA insertion line (Additional file 3: Figure S2).

Wild-type (WT) and mutant seeds were surface sterilized and grown in hydroponic culture [49] in the same conditions as described by Keunen et al. [35]. After 19 days, Hoagland solution was supplemented with $0.5 \mu \mathrm{M} \mathrm{CuSO}_{4}, 2 \mu \mathrm{M} \mathrm{CuSO}_{4}, 5 \mu \mathrm{M} \mathrm{CdSO}_{4}$ or $5 \mu \mathrm{M}$ $\mathrm{CdSO}_{4}+$ extra $\mathrm{CuSO}_{4}\left(0.5,1\right.$ or $\left.2 \mu \mathrm{M} \mathrm{CuSO}_{4}\right)$ and plants were harvested after an exposure time of 2,24 and $72 \mathrm{~h}$, to examine immediate responses, responses after 1 full 
circadian day and responses at metabolic homeostasis respectively. Copper deficient plants were grown from germination on in adapted $\mathrm{Cu}$ deficient Hoagland solution $(0.5 \mathrm{nM} \mathrm{Cu})$. Root and leaf (entire rosette) samples were taken, snap frozen in liquid nitrogen and stored at $-70{ }^{\circ} \mathrm{C}$ prior to lipid peroxidation analysis and gene expression analysis. Samples for element analysis were dried prior to extraction.

For root growth analysis, seeds were surface sterilized and grown on vertical agar plates. The preparation of the germination plates was performed as described by Remans et al. [38] with an adjusted $\mathrm{Cu}$ concentration (final concentration of $100 \mathrm{nM}$ ) and after 7 days of growth, seedlings were transferred to treatment plates and exposed for another 7 days to 1,3 and $10 \mu \mathrm{M} \mathrm{CuSO}_{4}$ or $0.5,1.5$ and $5 \mu \mathrm{M} \mathrm{CdSO}_{4}$. Plates were scanned on a flatbed scanner at $600 \mathrm{dpi}$ and root growth was analysed using the Optimas6 Image Analysis Software (Media Cybernetics).

\section{Element analysis}

Fresh root samples (175-400 mg FW) were washed for 15 min with $10 \mathrm{mM} \mathrm{Pb}\left(\mathrm{NO}_{3}\right)_{2}$ at $4{ }^{\circ} \mathrm{C}$ and rinsed with distilled water, while leaf samples (400-1000 mg FW) were only rinsed with distilled water. Samples were oven-dried ( $60{ }^{\circ} \mathrm{C}$ for 3 weeks), weighed, digested with $70 \% \mathrm{HNO}_{3}$ in a heat block and dissolved in $5 \mathrm{ml}$ of $2 \% \mathrm{HCl}$. Copper and $\mathrm{Cd}$ concentrations were measured via inductively coupled plasma-atomic emission spectrometry (ICP-AES, Perkin-Elmer, 1100B, USA). Blanks (only $\mathrm{HNO}_{3}$ ) and standard references (NIST Spinach 1570a) were included.

\section{Lipid peroxidation analysis}

The amount of thiobarbituric acid reactive metabolites (TBArm), as a measure of lipid peroxidation, was determined spectrophotometrically. Roots and leaves (50-100 mg FW) were homogenized in $1 \mathrm{ml}$ of $0.1 \%$ trichloroacetic acid (TCA), centrifuged (10 min, $20000 \mathrm{~g}$, $4{ }^{\circ} \mathrm{C}$ ) and 3.5 times diluted in $0.5 \%$ TBA. After heating to $95{ }^{\circ} \mathrm{C}$ for $30 \mathrm{~min}$, samples were put on ice for $5 \mathrm{~min}$ and centrifuged. The absorbance was measured at $532 \mathrm{~nm}$ and corrected for unspecific absorbance at $600 \mathrm{~nm}$. The amount of TBA reactive metabolites was calculated using the law of Beer-Lambert $\left(\varepsilon=155 \mathrm{mM}^{-1} \mathrm{~cm}^{-1}\right)$.

\section{Gene expression analysis}

Frozen tissues (50-75 mg FW) were disrupted using two stainless steel beads and the Retsch Mixer Mill MM2000 (Retsch, Haan, Germany) under frozen conditions. Total RNA was extracted using the RNAqueous Kit (Life Technologies, Carlsbad, CA, USA) according to manufacturer's instructions. RNA concentration and purity was determined spectrophotometrically on the NanoDrop ND-1000 (ThermoScientific, Wilmington, DE, USA). The cDNA for the pri-miRNA screening experiment had an RNA input of $3.2 \mu \mathrm{g}$ that was DNase treated (Turbo DNA-freeTM kit, Life Technologies) and reverse transcribed using SuperScriptTM III Reverse Transcriptase (Life Technologies) in a $30 \mu \mathrm{l}$ reaction according to manufacturer's instructions. The cDNA for the experiment using the $s p l 7$ knockout mutant, has an RNA input of $1 \mu \mathrm{g}$ that was DNase treated (Turbo DNAfreeTM kit, Life Technologies) and reverse transcribed using the High-Capacity cDNA Reverse Transcription Kit (Life Technologies) according to manufacturer's instructions. A 10-fold dilution of all the cDNA of both experiments was made using $1 / 10$ diluted TE buffer $(1 \mathrm{mM}$ Tris-HCL, $0.1 \mathrm{mM}$ EDTA, pH 8.0, Sigma-Aldrich, Belgium) and stored at $-20{ }^{\circ} \mathrm{C}$.

Quantitative PCR analysis was performed with the 7900HT Fast Real-Time PCR System (Life Technologies). For the pri-miRNA screening, the pri-miRNA platform [14] was used and reactions contained Fast SYBR Green Master Mix (Life Technologies), $500 \mathrm{nM}$ of a gene-specific forward and reverse primer, and $1 \mu \mathrm{l}$ of the diluted cDNA in a final volume of $10 \mu \mathrm{l}$. For target genes, primers were designed using primer express 2.0 and a BLAST was performed (http://www.arabidopsis.org/Blast/index.jsp) to check specificity (Additional file 4: Table S2). A two-fold dilution series of a pooled sample (all cDNAs of the experiment) was used to create a standard curve for the evaluation of primer efficiencies that were accepted when they were within a range between 80 and $100 \%$ (measured over 6 dilution points). PCR amplifications were performed at universal cycling conditions and contained Fast SYBR Green Master Mix, $300 \mathrm{~nm}$ of a gene-specific forward and reverse primer, and $2.5 \mu \mathrm{l}$ of the diluted cDNA in a final volume of $10 \mu \mathrm{l}$.

For the gene expression analysis of mature miRNAs, total RNA was extracted using the mirVana miRNA isolation kit (Life Technologies, Carlsbad, CA, USA) according to manufacturer's instructions. RNA concentration and purity was determined spectrophotometrically on the NanoDrop ND-1000. Multiplex reverse transcription and Real-time qPCR were performed using Taqman microRNA assays (Life Technologies, Carlsbad, CA, USA).

All relative expression levels were calculated as $2^{-\Delta C q}$ and normalized by the geometric average of $2^{-\Delta C q}$ values of minimum three reference genes selected by the GrayNorm algorithm [50]. Data of treatment effects are expressed relative to the control of its own genotype set at 1.00. For some genes (pri-miR167c, pri-miR397a, pri-miR857) expression was not detected after 40 cycli, neither after 60 cycli under control conditions. In that case, cyclic threshold was set at 40 for the control samples and thereby treatment effects could be calculated and expressed relative to the control. The calculated and represented treatment effects are therefore minimal fold changes when expression was undetermined after 40 cycli under control conditions. All details of 
the workflow according to the Minimum Information for publication of Quantitative real-time PCR Experiments (MIQE) guidelines as described by Bustin et al. [51] are shown in Additional file 5: Table S3.

\section{Statistical analysis}

Statistical analysis was performed using R (version 2.15.1; R Foundation for Statistical Computing, Vienna, Austria). Normal distribution of the datasets was tested using the Shapiro-Wilk test and homoscedasticity was evaluated with the Bartlett's test. If necessary, transformations of the datasets were applied. Gene expression data were always $\log$ transformed. Significant differences were determined using ANOVA test and Tukey correction. If the assumption of normality was not fulfilled, a non-parametrical ANOVA test (Kruskal-Wallis) and correction with pairwise Wilcoxon rank sum test was applied.

\section{Additional files}

Additional file 1: Cq values of 180 pri-miRNAs in leaves and roots
measured using an RT-qPCR platform (XLSX $124 \mathrm{~kb})$

Additional file 2: Lipid peroxidation in leaves and roots of $A$. thaliana wildtype and spl7 knockout plants. Nineteen-days-old plants were exposed for $24 \mathrm{~h}$ to $2 \mu \mathrm{M}$ CuSO4, $5 \mu \mathrm{M}$ CdSO4 or grown under control conditions. Data are mean \pm S.E. of 4 biological replicates. Significant treatment differences $(P<0.01)$ after two-way ANOVA test and Tukey correction are indicated with an asterisk $\left(^{*}\right)$. There were no genotype differences. (DOCX $34 \mathrm{~kb}$ )

Additional file 3: Verification of the T-DNA insertion in the spl7 mutant. Primers were designed using T-DNA primer design. (DOCX $32 \mathrm{~kb}$ )

Additional file 4: Forward and reverse primers used to determine gene expression levels via quantitative real-time PCR. E-E-jn, exon-exon junction; E-I-b, exon-intron boundary; YLS, yellow-leaf-specific; UBQ10, ubiquitin; ACT, actin ; EF, elongation factor; APS, ATP sulfurylase; SULTR, sulfate transporter; LAC, laccase; CSD, Cu/Zn superoxide dismutase; FSD, Fe superoxide dismutase. *Pri-miRNA primer concentrations were increased to $900 \mathrm{nM}$. (DOCX $18 \mathrm{~kb}$ )

Additional file 5: Quantitative real-time PCR parameters according to the Minimum Information for publication of Quantitative real-time PCR Experiments (MIQE) guidelines derived from Bustin et al. [51]. (DOCX $16 \mathrm{~kb}$ )

\section{Acknowledgements}

We thank Carine Put and Ann Wijgaerts for their skilful technical assistance and we are grateful to the Max Planck Institute of Molecular Plant Physiology (Potsdam-Golm, Germany) to give the opportunity to use the pri-miRNA platform.

\section{Funding}

This work was supported by Hasselt University by a PhD grant for Heidi Gielen and through the Methusalem project [08M03VGRJ].

\section{Availability of data and materials}

The data sets supporting the results of this article are included within the article and its additional files.

\section{Authors' contributions}

HG performed most of the experiments under the supervision of TR, JV and AC. HG, TR and AC participated in the design of experiments and work progress discussions. HG wrote the manuscript and TR and AC assisted with writing the manuscript. All authors revised the manuscript critically for important intellectual content, and read and approved the final manuscript.

\section{Competing interests}

The authors declare that they have no competing interests.

Ethics approval and consent to participate

Not applicable.

Received: 30 March 2016 Accepted: 14 June 2016

Published online: 28 June 2016

\section{References}

1. Khraiwesh B, Zhu J-K, Zhu J. Role of miRNAs and siRNAs in biotic and abiotic stress responses of plants. Biochim Biophys Acta. 2012;1819:137-48.

2. Palatnik JF, Allen E, Wu X, Schommer C, Schwab R, Carrington JC, et al. Control of leaf morphogenesis by microRNAs. Nature. 2003:425:257-63.

3. Guo H, Xie Q, Fei J, Chua N. MicroRNA Directs mRNA Cleavage of the Transcription Factor NAC1 to Downregulate Auxin Signals for Arabidopsis Lateral Root Development. Plant Cell. 2005;17(May):1376-86.

4. Laufs P, Peaucelle A, Morin H, Traas J. MicroRNA regulation of the CUC genes is required for boundary size control in Arabidopsis meristems. Development. 2004;131:4311-22.

5. Zhou X, Wang G, Zhang W. UV-B responsive microRNA genes in Arabidopsis thaliana. Mol Syst Biol. 2007;3:1-10.

6. Kutter C, Schöb H, Stadler M, Meins F, Si-Ammour A. MicroRNA-mediated regulation of stomatal development in Arabidopsis. Plant Cell. 2007;19:2417-29.

7. Liu H-H, Tian X, Li Y-J, Wu C-A, Zheng C-C. Microarray-based analysis of stress-regulated microRNAs in Arabidopsis thaliana. RNA. 2008;14:836-43.

8. Jones-Rhoades MW, Bartel DP. Computational identification of plant microRNAs and their targets, including a stress-induced miRNA. Mol Cell. 2004;14:787-99.

9. Kawashima CG, Yoshimoto N, Maruyama-Nakashita A, Tsuchiya YN, Saito $\mathrm{K}$, Takahashi H, et al. Sulphur starvation induces the expression of microRNA-395 and one of its target genes but in different cell types. Plant J. 2009;57:313-21.

10. Kawashima CG, Matthewman CA, Huang S, Lee B-R, Yoshimoto N, Koprivova A, et al. Interplay of SLIM1 and miR395 in the regulation of sulfate assimilation in Arabidopsis. Plant J. 2011;66:863-76.

11. Bari R, Pant BD, Stitt M, Scheible W-R. PHO2, MicroRNA399, and PHR1 Define a Phosphate-Signaling Pathway in Plants. Plant Physiol. 2006;141(July):988-99.

12. Chiou T, Aung K, Lin S, Wu C, Chiang S, Su C. Regulation of Phosphate Homeostasis by MicroRNA in Arabidopsis. Plant Cell. 2006;18(February):412-21.

13. Fujii $H$, Chiou TJ, Lin SI, Aung K, Zhu JK. A miRNA involved in phosphatestarvation response in Arabidopsis. Curr Biol. 2005;15:2038-43.

14. Pant BD, Musialak-Lange M, Nuc P, May P, Buhtz A, Kehr J, et al. Identification of nutrient-responsive Arabidopsis and rapeseed microRNAs by comprehensive real-time polymerase chain reaction profiling and small RNA sequencing. Plant Physiol. 2009;150:1541-55.

15. Gielen H, Remans T, Vangronsveld J, Cuypers A. MicroRNAs in Metal Stress: Specific Roles or Secondary Responses? Int J Mol Sci. 2012;13:15826-47.

16. Zhou ZS, Huang SQ, Yang ZM. Bioinformatic identification and expression analysis of new microRNAs from Medicago truncatula. Biochem Biophys Res Commun. 2008;374:538-42.

17. Xie FL, Huang SQ, Guo K, Xiang AL, Zhu YY, Nie L, et al. Computational identification of novel microRNAs and targets in Brassica napus. FEBS Lett. 2007:581:1464-74

18. Huang SQ, Xiang AL, Che LL, Chen S, Li H, Song JB, et al. A set of miRNAs from Brassica napus in response to sulphate deficiency and cadmium stress. Plant Biotechnol J. 2010;8:887-99.

19. Huang SQ, Peng J, Qiu CX, Yang ZM. Heavy metal-regulated new microRNAs from rice. J Inorg Biochem. 2009;103:282-7.

20. Ding Y, Chen Z, Zhu C. Microarray-based analysis of cadmium-responsive microRNAs in rice (Oryza sativa). J Exp Bot. 2011;62:3563-73.

21. Sunkar R, Kapoor A, Zhu J. Posttranscriptional Induction of Two Cu/Zn Superoxide Dismutase Genes in Arabidopsis Is Mediated by Downregulation of miR398 and Important for Oxidative Stress Tolerance. Plant Cell. 2006;18(August):2051-65.

22. Cuypers A, Smeets K, Ruytinx J, Opdenakker K, Keunen E, Remans T, et al. The cellular redox state as a modulator in cadmium and copper responses in Arabidopsis thaliana seedlings. J Plant Physiol. 2011;168:309-16.

23. Abdel-Ghany SE, Pilon M. MicroRNA-mediated systemic down-regulation of copper protein expression in response to low copper availability in Arabidopsis. J Biol Chem. 2008;283:15932-45. 
24. Yamasaki H, Hayashi M, Fukazawa M, Kobayashi Y, Shikanai T. SQUAMOSA Promoter Binding Protein-Like7 Is a Central Regulator for Copper Homeostasis in Arabidopsis. Plant Cell. 2009;21:347-61.

25. Yamasaki H, Abdel-Ghany SE, Cohu CM, Kobayashi Y, Shikanai T, Pilon M. Regulation of copper homeostasis by micro-RNA in Arabidopsis. J Biol Chem. 2007:282:16369-78.

26. Valdés-López O, Yang SS, Aparicio-Fabre R, Graham PH, Reyes JL, Vance CP, et al. MicroRNA expression profile in common bean (Phaseolus vulgaris) under nutrient deficiency stresses and manganese toxicity. New Phytol. 2010;187:805-18

27. Lima JC, Arenhart RA, Margis-Pinheiro M, Margis R. Aluminum triggers broad changes in microRNA expression in rice roots. Genet Mol Res. 2011;10:2817-32.

28. Ding Y-F, Zhu C. The role of microRNAs in copper and cadmium homeostasis. Biochem Biophys Res Commun. 2009;386:6-10.

29. Zhou ZS, Zeng HQ, Liu ZP, Yang ZM. Genome-wide identification of Medicago truncatula microRNAs and their targets reveals their differential regulation by heavy metal. Plant, Cell Environ. 2012;35:86-99.

30. Zhou ZS, Song JB, Yang ZM. Genome-wide identification of Brassica napus microRNAs and their targets in response to cadmium. J Exp Bot. 2012;63:4597-613

31. Krznaric E, Verbruggen N, Wevers JHL, Carleer R, Vangronsveld J, Colpaert JV. Cd-tolerant Suillus luteus: a fungal insurance for pines exposed to $\mathrm{Cd}$. Environ Pollut. 2009:157:1581-8.

32. Keunen E, Truyens S, Bruckers L, Remans T, Vangronsveld J, Cuypers A. Survival of $\mathrm{Cd}$-exposed Arabidopsis thaliana: are these plants reproductively challenged? Plant Physiol Biochem. 2011;49:1084-91.

33. Adriaensen K, Vralstad T, Noben J-P, Vangronsveld J, Colpaert JV. CopperAdapted Suillus luteus, a Symbiotic Solution for Pines Colonizing Cu Mine Spoils. Appl Environ Microbiol. 2005;71:7279-84.

34. Smeets K, Opdenakker K, Remans T, Van Sanden S, Van Belleghem F, Semane $B$, et al. Oxidative stress-related responses at transcriptional and enzymatic levels after exposure to $\mathrm{Cd}$ or $\mathrm{Cu}$ in a multipollution context. J Plant Physiol. 2009;166:1982-92.

35. Keunen E, Remans T, Opdenakker K, Jozefczak M, Gielen H, Guisez Y, et al. A mutant of the Arabidopsis thaliana LIPOXYGENASE1 gene shows altered signalling and oxidative stress related responses after cadmium exposure. Plant Physiol Biochem. 2013;63:272-80.

36. Maksymiec W, Wójcik M, Krupa Z. Variation in oxidative stress and photochemical activity in Arabidopsis thaliana leaves subjected to cadmium and excess copper in the presence or absence of jasmonate and ascorbate. Chemosphere. 2007;66:421-7.

37. Panda SK. Impact of copper on reactive oxygen species, lipid peroxidation and antioxidants in Lemna minor. Biol Plant. 2008;52:561-4.

38. Remans T, Thijs S, Truyens S, Weyens N, Schellingen K, Keunen E, et al. Understanding the development of roots exposed to contaminants and the potential of plant-associated bacteria for optimization of growth. Ann Bot. 2012;110:239-52.

39. Keunen $E$, Jozefczak M, Remans T, Vangronsveld J, Cuypers A. Alternative respiration as a primary defence during cadmium-induced mitochondrial oxidative challenge in Arabidopsis thaliana. Environ Exp Bot. 2013;91:63-73.

40. Barciszewska-Pacak M, Milanowska K, Knop K, Bielewicz D, Nuc P, Plewka P, et al. Arabidopsis microRNA expression regulation in a wide range of abiotic stress responses. Front Plant Sci. 2015;6(June):410.

41. Gayomba SR, Jung H, Yan J, Danku J, Rutzke MA, Bernal M, et al. The CTR/ COPT-dependent copper uptake and SPL7-dependent copper deficiency responses are required for basal cadmium tolerance in $\mathrm{A}$. thaliana. Metallomics. 2013;5:1262-75.

42. Sharma SS, Dietz K-J. The relationship between metal toxicity and cellular redox imbalance. Trends Plant Sci. 2009;14:43-50.

43. Cuypers A, Keunen E, Bohler S, Jozefczak M, Opdenakker K, Gielen H, et al. Cadmium and copper stress induce a cellular oxidative challenge leading to damage versus signalling. In: Gupta DKG, Sandalio LM, editors. Metal Toxicity in Plants: Perception, Signaling and Remediation. Berlin, Heidelberg: Springer-Verlag GmbH; 2012. p. 65-90.

44. DalCorso G, Farinati S, Maistri S, Furini A. How plants cope with cadmium: staking all on metabolism and gene expression. J Integr Plant Biol. 2008;50:1268-80.

45. Yoshihara T, Hodoshima H, Miyano Y, Shoji K, Shimada H, Goto F. Cadmium inducible Fe deficiency responses observed from macro and molecular views in tobacco plants. Plant Cell Rep. 2006;25:365-73.
46. Xu SS, Lin SZ, Lai ZX. Cadmium impairs iron homeostasis in Arabidopsis thaliana by increasing the polysaccharide contents and the iron-binding capacity of root cell walls. Plant Soil. 2015;392:71-85.

47. Garcia-Molina A, Xing S, Huijser P. Functional characterisation of Arabidopsis SPL7 conserved protein domains suggests novel regulatory mechanisms in the Cu deficiency response. BMC Plant Biol. 2014;14:231.

48. Alonso JM, Stepanova AN, Leisse TJ, Kim CJ, Chen H, Shinn P, et al. Genome-wide insertional mutagenesis of Arabidopsis thaliana. Science (80-). 2003;301:653-7.

49. Smeets K, Ruytinx J, Van Belleghem F, Semane B, Lin D, Vangronsveld J, et al. Critical evaluation and statistical validation of a hydroponic culture system for Arabidopsis thaliana. Plant Physiol Biochem. 2008;46:212-8.

50. Remans T, Keunen E, Bex GJ, Smeets K, Vangronsveld J, Cuypers A. Reliable Gene Expression Analysis by Reverse Transcription-Quantitative PCR: Reporting and Minimizing the Uncertainty in Data Accuracy. Plant Cell. 2014;26:3829-37.

51. Bustin SA, Benes V, Garson JA, Hellemans J, Huggett J, Kubista M, et al. The MIQE guidelines:Minimum Information for publication of quantitative realtime PCR experiments. Clin Chem. 2009;55:611-22.

\section{Submit your next manuscript to BioMed Central and we will help you at every step:}

- We accept pre-submission inquiries

- Our selector tool helps you to find the most relevant journal

- We provide round the clock customer support

- Convenient online submission

- Thorough peer review

- Inclusion in PubMed and all major indexing services

- Maximum visibility for your research

Submit your manuscript at www.biomedcentral.com/submit
) Biomed Central 